\title{
A percepção da ambiência térmica e as estratégias de adaptação: estudo de caso com idosos no clima tropical
}

\author{
The perception of the thermal ambience and occupant \\ behaviour: a case study with elderly people in a tropical \\ climate
}

\section{Julio Gonçalves da Silveira \\ Mayara Cynthia Sousa \\ Solange Maria Leder}

\section{Resumo}

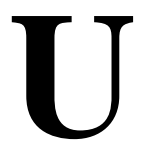

ma parcela considerável das pesquisas sobre o conforto térmico não considera a dinâmica da relação entre os usuários e a edificação, bem como há poucos estudos sobre conforto térmico e o idoso, especialmente em clima tropical. Esta pesquisa abordou a sensação e a percepção térmica em conjunto habitacional com as estratégias de adaptação ao ambiente, tendo como população indivíduos acima de 60 anos. Para isso, foram coletados dados mediante entrevistas semiestruturadas com 90 residentes de três conjuntos habitacionais para idosos, de caráter social e mesmo projeto arquitetônico, localizados nas cidades paraibanas de João Pessoa, Campina Grande e Cajazeiras. Os dados foram analisados por meio de técnicas estatísticas descritivas e inferenciais. Os idosos apresentaram tendência a preferir condições térmicas mais amenas àquelas vivenciadas por eles na habitação em análise. A ventilação natural é considerada uma variável importante para o conforto térmico, contudo os entrevistados relatam fechar as esquadrias para evitar a entrada de insetos e animais, dificultando a ventilação natural. Também foi identificado que fatores culturais e a necessidade de segurança interferem no fechamento das aberturas. Não foram encontradas correlações significativas entre o sexo dos entrevistados e suas respostas.

Palavras-chave: Conforto térmico. Comportamento dos usuários. Idosos.

\begin{abstract}
A considerable portion of the research on thermal comfort fails to undertake a comprehensive analysis including the relationship between residents and their buildings. It is also noteworthy that there are but a few studies on thermal comfort and the elderly, especially in tropical climates. Thus, this research study looks into sensation and thermal perception alongside strategies of adaptation to the environment, investigating a population of individuals over 60 years old, forming a sample of 90 respondents. The object of this study comprised 3 social housing units for the elderly located in the cities of Paraíba, João Pessoa, Campina Grande, and Cajazeiras. Data were collected through semi-structured interviews, and analysed using descriptive and inferential statistical techniques. The researchers found that the elderly showed a preference for thermal environmental conditions milder than those prevailing at the time of interview. Natural ventilation is normally considered an important variable for thermal comfort, however, the respondents reported closing openings to prevent the entry of insects and animals, making natural ventilation difficult, and contributing to their thermal discomfort. It was also found that both cultural and security factors influence the closing of doors and windows. No significant correlation was found between the respondents' gender and their answers.

Keywords: Thermal comfort. Occupants' behaviour. Elderly.
\end{abstract}

SILVEIRA, J. G. da; SOUSA M. C.; LEDER, S. M. percepção da ambiência térmica e as estratégias de adaptação: estudo de caso com idosos no clima tropical. Ambiente Construído, Porto Alegre, v. 20, n. 4, p. 99-121, out./dez. 2020.

ISSN 1678-8621 Associação Nacional de Tecnologia do Ambiente Construído. http://dx.doi.org/10.1590/s1678-86212020000400462 


\section{Introdução}

A compreensão do comportamento dos usuários é um parâmetro importante para a concepção e a avaliação do desempenho das edificações, especialmente aquelas ventiladas naturalmente. Parcela significativa dos estudos voltados ao conforto ambiental analisa e correlaciona as condições ambientais com a satisfação dos usuários, e há uma significativa lacuna sobre as estratégias que esses usuários possam eventualmente adotar para alcançar o estado de satisfação com a ambiência térmica (KOWALTOWSKI; BERNARDI, 2001), de modo que estratégias simples capazes de melhorar o conforto térmico são frequentemente ignoradas (SIMÕES, 2018).

No tocante aos usuários e ao conforto térmico, destaca-se que os modelos preditivos de conforto desconsideram as diferenças decorrentes da idade. O corpo humano tem mudanças significativas na fase idosa, com redução da taxa metabólica basal, aumento do débito cardíaco (volume de sangue bombeado pelo coração em $1 \mathrm{~min}$ ), redução da sensibilidade nas extremidades do corpo e aumento da taxa de gordura, que substitui a massa muscular, além de possíveis alterações de saúde, como hipertensão e diabetes (PANTAVOU et al., 2011; MA; XIONG; LIAN, 2017; SALATA et al., 2018).

O cenário populacional mundial aponta uma mudança na pirâmide etária, influência das transformações ocorridas na dinâmica populacional, convergindo no aumento da população idosa. No Brasil, estudos de projeções da população brasileira efetuados pelo Instituto Brasileiro de Geografia e Estatística (IBGE) traduzem essa mudança, como pode ser observado na Figura 1. A tendência do envelhecimento populacional acentua ainda mais a importância de estudos voltados a esse público.

Pesquisas apontam que os idosos têm uma percepção térmica diferente da dos adultos (TOCHIHARA et al., 2011; DAANEM; HERWEIJER, 2015; PANET, 2018; GIAMALAKI; KOLOKOTSA, 2019) devido a alterações fisiológicas e à diminuição da sensibilidade dos mecanismos termorreguladores. Adequações para garantia do conforto térmico, com ênfase na regulação térmica, fazem parte do cotidiano do sistema termorregulador humano. Entretanto, em virtude das limitações citadas, os idosos podem se encontrar em um estado vulnerável a variações e extremos de temperatura, pois seu organismo não responde da mesma forma que um mais jovem, havendo, assim, a necessidade de um ambiente que garanta o conforto térmico e que possa ser adaptado facilmente.

\section{Figura 1 - Pirâmide etária do Brasil em 2018 e projeção para 2060}

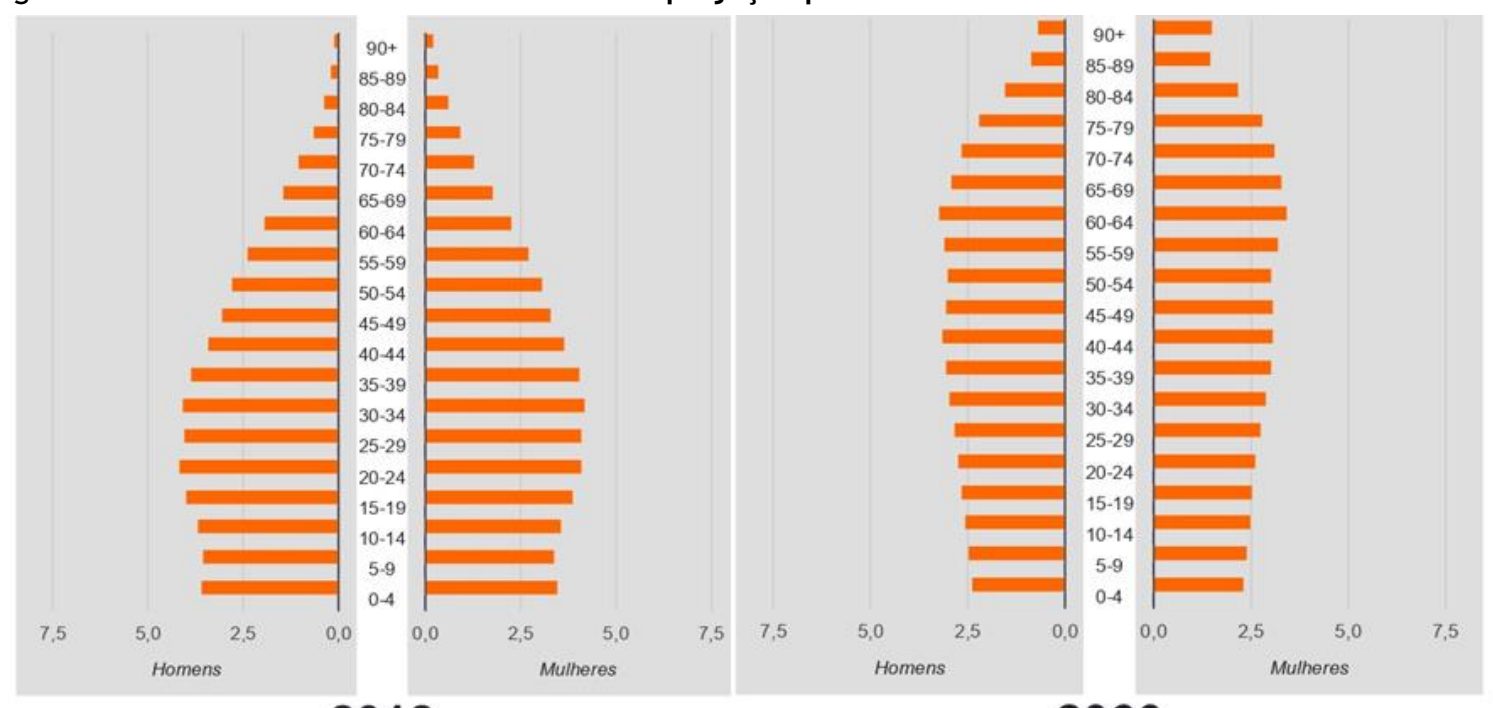

Exibindo ano de: 2018

Exibindo ano de: 2060

Fonte: adaptada do IBGE (INSTITUTO..., 2020). 
Fundamentada na escassez de pesquisas sobre conforto térmico considerando idosos e, especialmente, as ações destes de adaptação ou melhoria das condições ambientais térmicas, esta pesquisa foi esboçada. Isso posto, com base na percepção de idosos, o objetivo deste artigo é analisar a sensação térmica, a percepção térmica e estratégias adaptativas que possam inibir ou promover o conforto térmico em ambientes residenciais. $\mathrm{O}$ objeto teórico da pesquisa são os idosos e sua relação com a ambiência térmica, enquanto o objeto empírico compreende três conjuntos habitacionais com idosos, construídos em diferentes localidades climáticas no Nordeste brasileiro, nos quais entrevistas semiestruturadas foram realizadas e condições ambientais monitoradas.

\section{Referencial teórico}

A orientação solar, a compacidade, a proteção solar, o desempenho dos fechamentos opacos e transparentes, a estanqueidade ao ar e a ventilação do edifício são variáveis que impactam no desempenho térmico da edificação e no conforto térmico do usuário. A ventilação natural tem um desempenho fundamental no condicionamento passivo, sendo um dos fundamentos do conceito que originou a norma PassivHaus (WASSOUF, 2014) e os modelos preditivos adaptativos da norma ASHRAE 55 (AMERICAN..., 2017). O projeto arquitetônico baseado no uso de estratégias bioclimáticas aliado a sistemas de refrigeração e aquecimento eficientes resulta em edificações com menor consumo de energia (DE VECCHI, 2015; OROSA; OLIVEIRA, 2010).

A eficiência do uso de algumas técnicas passivas de climatização, como a ventilação cruzada, pode ser influenciada pelo comportamento do usuário. Em ambientes desconfortáveis, os usuários realizam ações para restabelecer o nível de conforto térmico e alcançar melhores condições no interior do edifício (NICOL; HUMPREYS, 2002; DE DEAR; BRAGER; COOPER, 1997). Sobre a ação do usuário em relação ao ambiente ainda há muitas incógnitas, como a carência de modelos de predição da interação dos ocupantes com a edificação (DE VECCHI, 2015; ANDERSEN; FABI; CORGNATI, 2016).

Em relação aos usuários, sabe-se que os modelos preditivos de conforto comumente não consideram diferenças individuais como a idade. Por outro lado, o corpo humano tem mudanças significativas na fase idosa, as quais podem impactar na sensação e na percepção de conforto térmico (PANTAVOU et al., 2011; MA; XIONG; LIAN, 2017; SALATA et al., 2018). Assim, os idosos são mais vulneráveis a variações bruscas nas condições ambientais e especialmente sensíveis a extremos de temperatura do ar, pois seu organismo não responde da mesma forma que os demais indivíduos.

\section{Estratégias de adaptação}

O usuário interage com o edifício, comportamento que influencia no desempenho da edificação. Por isso, na predição do desempenho da edificação, deve-se considerar a interação entre a edificação, os usuários, os equipamentos e o clima externo (HALDI; ROBINSON, 2011). O edifício pode ser comparado a um equipamento cuja manipulação requer orientação para que se possa obter um desempenho satisfatório. A identificação dos padrões de comportamento dos usuários fornece subsídios para o desenvolvimento de estratégias de treinamento e aprendizagem de boas práticas no uso da edificação. Destarte, o comportamento dos usuários pode reduzir ou aumentar o consumo energético da edificação para atingir condições térmicas aceitáveis para os usuários.

O conforto térmico adaptativo tem como base o entendimento de que as pessoas se adaptam ao ambiente para alcançar o conforto. Em um ambiente real, as pessoas utilizam várias estratégias, de acordo com suas preferências, para chegar à condição de conforto. Nessa abordagem, os usuários não são considerados elementos inertes, mas interagem com o ambiente (BRAGER; PALIAGA; DE DEAR, 2004; NICOL; HUMPHREYS, 2002).

Assim, o usuário tem papel ativo na resposta aos estímulos térmicos do ambiente, ou seja, os ocupantes interagem com o ambiente utilizando meios de adaptação fisiológica, comportamental e psicológica para atingir uma situação de conforto (LIU; YAO; MCCLOY, 2012). A adaptação físiológica está associada à regulação térmica do corpo humano, como vasodilatação e vasoconstrição, e compreende duas categorias: adaptação genética e aclimatação. Experiências e expectativas térmicas estão associadas à adaptação psicológica. A adaptação comportamental pode ser de natureza pessoal, tecnológica ou cultural. As ações comportamentais são desencadeadas por variáveis do ambiente interno e externo, e a variabilidade e o acesso aos sistemas de controle indicam as oportunidades adaptativas que os usuários têm (DE DEAR; BRAGER; COOPER, 1997). 
Acerca de espaços ventilados naturalmente, observou-se que os usuários possuem maior faixa de condições ambientais térmicas aceitáveis se comparado a ambientes condicionados artificialmente, que se correlaciona diretamente com a temperatura externa à edificação (BRAGER; PALIAGA; DE DEAR, 2004). O conhecimento dos limites de conforto e, principalmente, das estratégias de adaptação dos usuários às condições ambientais (com ou sem uso de energia) tem sido reconhecido como fundamental para a previsão do desempenho da edificação.

No clima quente e úmido, a ventilação cruzada permanente é uma estratégia recomendada (ABNT, 2003). Assim, o manuseio das esquadrias (abertura e fechamento) é uma ação do usuário que possibilita o resfriamento da edificação (BAKER; STANDEVEM, 1996). A atuação do usuário no manuseio das esquadrias depende não somente da possibilidade de controle delas, mas também do tipo de controle, da dimensão e da forma da abertura, sua localização, da distância e da acessibilidade (barreiras), e até mesmo de questões de hierarquia no controle das condições ambientais. Indraganti et al. (2014) identificaram que, muitas vezes, os componentes da edificação são impedimentos à promoção da ventilação natural, como a dificuldade de acesso ou de manuseio da abertura, o que reduz a possibilidade do usuário em promover a ventilação natural.

Roetzel et al. (2010) destacam a temperatura do ar, a qualidade do ar interno e as variáveis externas (como o ruído e a poluição do ar) como fatores determinantes na ação do usuário de abrir ou fechar esquadrias. A frequência de abertura das esquadrias, o tempo em que elas permanecem abertas, a hora do dia, a estação do ano, entre outras, são variáveis que influenciam as condições térmicas internas. Os motivadores da ação de abrir e fechar as esquadrias, assim como o padrão de uso (rotina), ao longo do dia e do ano são questões relevantes para a predição das condições ambientais.

No estudo de D'Oca e Hong (2014), os principais motivadores para a abertura e o fechamento da janela são a temperatura do ar interna, a temperatura do ar externa e a hora do dia (início do expediente e início do dia para abertura, e final do dia e final do expediente para o fechamento). Variáveis como ruído ou ventos em excesso provenientes do exterior, visão, contato com o exterior, privacidade, segurança, regras em relação à indumentária, entre outras, podem influenciar a ação de abrir ou fechar as esquadrias.

Especificamente tratando dos motivos que conduzem o usuário a abrir ou fechar a janela, no estudo de Fabi et al. (2011) evidenciou-se que a condição térmica não é o único motivador para a ação de controle da abertura. Em geral, os fatores motivadores podem ser agrupados em cinco categorias: físico-ambiental, contextual, psicológica, fisiológica e social. A operação da abertura é motivada por variáveis do ambiente interno e externo:

(a) como variáveis externas destacam-se a temperatura do ar, a qualidade do ar, o tipo de abertura, a hora do dia e a época do ano; e

(b) as variáveis externas são a temperatura do ar, a radiação solar, a ventilação, a segurança, animais e a chuva.

Outro aspecto observado em pesquisas recentes diz respeito à percepção do usuário do potencial das ações individuais na promoção do conforto térmico. A pesquisa de Simões (2018), com enfoque nas autoconstruções, identificou que as alterações edílicas em residências tendem a impedir totalmente ou reduzir significativamente as possibilidades de ventilação e iluminação natural, destacando a importância de investigações com foco nesse aspecto.

\section{Envelhecimento}

O envelhecimento é caracterizado por um processo complexo e multifatorial. Embora as fases da vida ocorram através de um modelo linear (criança, adolescente, adulto e idoso), não existe uma precisão do início e término de cada fase, devido a uma diversidade de parâmetros que podem influenciar esses limites (SCHNEIDER; IRIGARAY, 2008). Os pesquisadores Schneider e Irigaray (2008) apontam que as fases da vida podem ser medidas através de aspectos cronológicos, biológicos, psicológicos e sociais, os quais, embora importantes para a compreensão do processo de envelhecimento, não podem ser considerados determinantes devido a seu aspecto multifatorial.

De acordo com Ramos (2003), parcela significativa de idosos possui no mínimo uma doença crônica, entretanto o autor discorda que uma velhice saudável seja resultado da ausência de doenças, acreditando que ela se caracteriza pela interação multidimensional entre suporte familiar, independência econômica, saúde física, saúde mental e integração social. 


\section{Conforto térmico de idosos}

Segundo Tochihara et al. (2011), por conta da redução da sensibilidade nas extremidades do corpo, acentuada com a idade, os idosos tendem a ter uma resposta mais lenta em relação às variações nas condições térmicas ambientais. Os autores também destacam que as mulheres tendem a ter mais sensibilidade térmica na parte superior do corpo e afirmam que existe diferença no tempo de reação à mudança de temperatura nas diferentes extremidades do corpo de acordo com o sexo do indivíduo (TOCHIHARA et al., 2011). A redução da sensibilidade pode ser significativa e, com o passar dos anos, pode ser mais severa, uma vez que a sensação e a percepção são de estabilidade térmica, apesar de o corpo estar em estresse térmico, condição que pode levar o idoso a quadros de hipotermia e hipertermia, o que favorece pneumonias e desidratação (TOCHIHARA et al., 2011).

Comparando o tempo de reação à mudança de temperatura do ar de idosos e adultos, Daanem e Herweijer (2015) investigaram a reação dos idosos à mudança de temperatura do ar após um período de aclimatação térmica e constaram que eles reagem mais lentamente às mudanças, entretanto a capacidade de aclimatação não é modificada com o tempo. Assim, é importante considerar que os idosos tendem a recorrer a meios de condicionamento artificial térmico quando sua sensação de desconforto é alta (GIAMALAKI; KOLOKOTSA, 2019).

De acordo com a Diretriz Brasileira de Hipertensão Arterial, os sintomas que estão ligados diretamente ao conforto térmico são a intolerância ao calor, a hipertermia e a taquicardia. Esses sintomas podem alterar de forma considerável segundo como a pessoa interage com o ambiente térmico. A hipertensão é um fator considerável para a pesquisa do conforto de idosos, pois estes representam $60 \%$ das pessoas com esse quadro clínico (MALACHIAS et al., 2016).

Outro quadro clínico que pode afetar a sensação térmica em idosos é a diabetes, de acordo com as Diretrizes da Sociedade Brasileira de Diabetes 2017-2018 (SOCIEDADE..., 2017), que tem como sintomas sudorese (suor excessivo), taquicardia, variabilidade da frequência cardíaca e sensação de boca seca. Estes podem ser confundidos com sintomas causados pelo calor e, assim, levar o usuário a uma avaliação errônea do conforto térmico. Assim como a hipertensão, a ocorrência de diabetes é maior em idosos, o que indica a relevância de considerar essa informação entre os indivíduos nos estudos sobre o ambiente térmico.

Os sintomas desses quadros clínicos podem e devem ser utilizados para a caracterização da sensação e preferência térmica para idosos, pois, ao garantir um ambiente confortável, se garantem as melhores condições para a manutenção da saúde do usuário da edificação. Um ambiente flexível, no qual o usuário possa interagir a fim de obter condições térmicas adequadas a suas exigências de conforto, contribui para a saúde e a realização das tarefas laborais (ORMANDY; EZRATTY, 2012).

Os idosos tendem a se sentir confortáveis termicamente em condições ambientais nas quais indivíduos em outras faixas etárias relatam desconforto (NOVIETO; ZHANG, 2010; CHINDAPOL et al., 2017; ROELOFSEN, 2017; VAN HOOF et al., 2017). Assim, observou-se que os idosos descreviam com maior frequência (quando comparado a grupos adultos) a sensação de neutralidade térmica tanto no inverno quanto no verão. Supostamente as alterações fisiológicas agem sobre a sensação térmica do idoso, induzindo-o a relatar uma sensação de neutralidade térmica quando as condições ambientais são de desconforto térmico (FAN et al., 2017; JIAO et al., 2017b; WANG; XIA; LU, 2017). O sexo e a obesidade também são variáveis que podem atuar na percepção da ambiência térmica (MACHADO; COELHO; COELHO, 2010).

Wang et al. (2019) verificaram que os idosos são mais sensíveis a mudanças na ordem de $3{ }^{\circ} \mathrm{C}$, ou seja, é necessário um acréscimo ou redução de $3{ }^{\circ} \mathrm{C}$ para que o indivíduo idoso perceba alteração nas condições térmicas do ambiente, contudo a preferência térmica é alterada apenas com mudanças na ordem de $5^{\circ} \mathrm{C}$. A exposição à diminuição repentina na temperatura do ar é mais prejudicial do que seu aumento súbito, com maior impacto na pressão arterial, nos batimentos cardíacos e na frequência respiratória.

Para obter o conforto térmico, a maioria dos idosos realiza a adaptação da vestimenta em vez da adaptação do ambiente, pois com a redução da taxa metabólica eles tendem a utilizar maior resistência térmica (clo) na indumentária, quando comparados com pessoas mais jovens. Além disso, entre os idosos, a mulher utiliza um "clo" ainda maior, embora no verão não tenha se verificado essa diferença (JIAO et al., 2017a).

\section{Método}

Esta pesquisa faz parte de um estudo amplo, no qual foram avaliadas, considerando indivíduos idosos e o ambiente deles, as seguintes variáveis: sensação térmica, percepção térmica, conforto térmico, preferência 
térmica, estratégias adaptativas, características antropométricas (altura, idade e peso), sexo, aspectos fisiológicos, variáveis ambientais (temperatura do ar, umidade do ar, velocidade do ar e temperatura radiante média), aspectos fisiológicos (pressão arterial, diabetes e dificuldade de locomoção) e rotinas de uso da residência.

Este artigo se configura na primeira etapa da pesquisa, ou seja, a análise da sensação térmica, da percepção térmica e das estratégias adaptativas que podem inibir ou promover o conforto térmico em ambientes residenciais. $\mathrm{O}$ estudo foi embasado no método experimental, através da coleta de dados subjetivos oriundos de entrevistas semiestruturadas e questionários. Os resultados obtidos foram analisados de modo descritivo e inferencial. As etapas metodológicas foram compostas em três partes:

(a) definição da amostra, elaboração das perguntas, estudos de campo piloto e aprovação no comitê de ética;

(b) coleta dos dados em campo; e

(c) análise descritiva e formulações estatísticas baseadas na teoria inferencial.

A investigação teve como foco as estratégias adotadas por idosos para a promoção do conforto térmico, assim como comparou preferências, sensações e percepções térmicas dos idosos (pessoas acima de 60 anos) em condomínios fechados de interesse social localizados em diferentes tipos de clima no Nordeste do Brasil.

\section{Objeto de estudo}

Os condomínios horizontais estudados estão implantados em três cidades:

(a) João Pessoa, situada no litoral;

(b) Campina Grande, na serra da Borborema; e

(c) Cajazeiras, no sertão.

As cidades apresentam características climáticas distintas por conta de sua localização geográfica e cota em relação ao nível do mar, conforme pode ser identificado na Figura 2.

A cidade de João Pessoa apresenta um clima tropical semiúmido com apenas 3 meses de período seco. Campina Grande, por sua vez, é considerada uma zona de transição entre duas regiões climáticas, o clima tropical semiúmido, com 4 a 5 meses de período seco, e o tropical semiárido, com 6 meses de período seco. A cidade de Cajazeiras tem como clima local o tropical semiárido mais rigoroso, com 8 meses de período seco no ano (Figura 3) (INSTITUTO..., 2002).

Segundo a NBR 15220-3 (ABNT, 2003), que divide o clima brasileiro em oito zonas climáticas, o estado da Paraíba é cortado por três zonas, a 6, a 7 e a 8. João Pessoa e Campina Grande estão localizadas na zona bioclimática 8 , e a cidade de Cajazeiras se encontra na zona bioclimática 7. Comparando as duas referências (IBGE x NBR 15220), observa-se que a principal distinção é a classificação da cidade de Campina Grande, uma vez que, segundo o IBGE, está em uma região de transição climática. Ressalta-se que o clima pode influenciar na forma como o usuário interage com a edificação.

Figura 2 - Corte com a distribuição das localidades em estudo

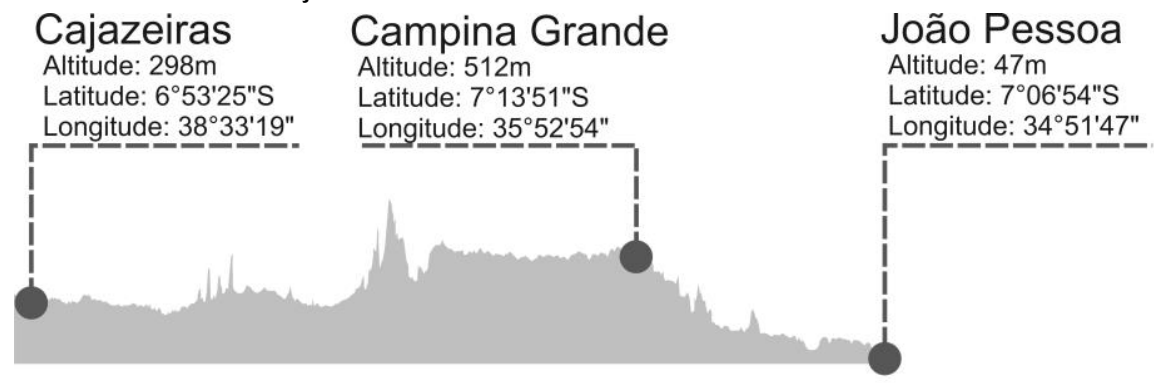

Fonte: adaptada do Google Earth Pro (2017).

104 Silveira, J. G. da; Sousa M. C.; Leder, S. M. 
Figura 3 - Zoneamento climático - IBGE e NBR 15220
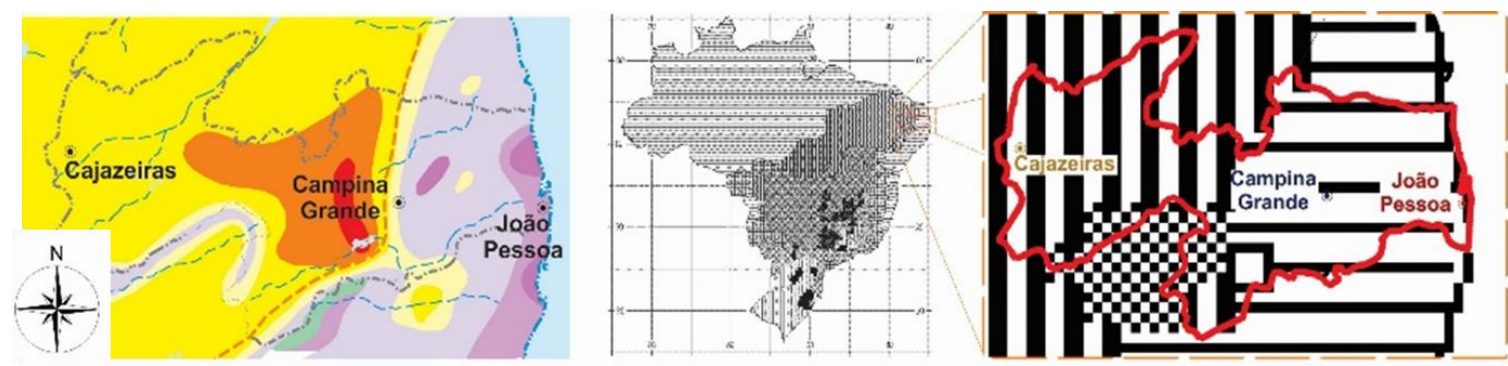

Fonte: adaptada de IBGE (INSTITUTO..., 2002) e ABNT (2003).

Nota: Legenda:

\begin{tabular}{|c|c|}
\hline Mapa de Clima do Brasil - IBGE & $\begin{array}{l}\text { Zoneamento Bioclimático } \\
\text { Brasileiro - NBR } 15220\end{array}$ \\
\hline Clima tropical úmido -3 meses de período seco & \\
\hline Clima tropical semiúmido - 4 a 5 meses de período seco & Zona bioclimática 8 \\
\hline Clima tropical semiárido - 6 meses de período seco & ||ㅐ| Zona bioclimática 7 \\
\hline Clima tropical semiárido -7 a 8 meses de período seco & Zona bioclimática 6 \\
\hline
\end{tabular}

As unidades habitacionais nos conjuntos em estudo estão distribuídas de modo a circundar uma praça central, estando a fachada frontal (na qual a porta de acesso à edificação está localizada) sempre voltada para a praça, o que resulta em diferentes orientações solares na implantação das residências. No conjunto de João Pessoa, as edificações possuem a fachada frontal com duas orientações: norte e sul. Nos condomínios de Campina Grande e Cajazeiras, as unidades habitacionais possuem orientações distintas, conforme pode ser visualizado na Figura 4.

Os condomínios são compostos de 20 blocos, cada um com duas unidades habitacionais geminadas, totalizando 40 habitações. As unidades habitacionais são geminadas por espelhamento de planta, cada unidade com área de $54,11 \mathrm{~m}^{2}$. O programa de necessidades possui terraço, sala de estar e jantar, cozinha e área de serviço integradas, quarto e banheiro social adaptado. A unidade habitacional foi projetada para um programa composto para duas pessoas, um casal ou idoso e acompanhante.

A planta e a fachada frontal podem ser vistas na Figura 5. A rampa de acesso, o terraço, a porta de entrada e a abertura da sala de estar e jantar estão situados na parte frontal da edificação. Na parte posterior da habitação estão o quarto, o banheiro e a área de serviço, e na fachada lateral (direita ou esquerda, a depender da célula habitacional analisada), a cozinha. As edificações não podem ser reformadas sem autorização da Companhia Estadual de Habitação Popular (CEHAP), de modo que elas mantêm preservadas suas características originais.

O projeto arquitetônico foi replicado nas três cidades e executado com sistema construtivo e materiais convencionais para a região onde foi implantado: piso cerâmico, alvenaria de tijolos cerâmicos de oito furos e laje inclinada com telhas cerâmicas (Figura 6). A cor externa é clara com detalhes em branco. Na cidade de Cajazeiras foi adicionado forro de gesso no interior da habitação.

\section{Sensação, percepção e estratégias de conforto térmico}

Os dados subjetivos obtidos em campo foram oriundos de entrevistas semiestruturadas realizadas com os moradores dos condomínios em estudo. A coleta de dados ocorreu na estação do verão, entre os dias 21 de janeiro e 16 de fevereiro. Os idosos foram direcionados a descrever sua residência termicamente, assim como suas ações de adaptação às condições térmicas.

A elaboração das perguntas foi submetida a dois testes piloto, objetivando uma aproximação com a realidade dos entrevistados. Como essa aplicação prévia demonstrou que os idosos se sentiam mais confortáveis com poucas opções como resposta, observou-se que as perguntas referentes a sensação, ventilação e percepção térmica eram expressas adequadamente em uma escala de 4 pontos (Quadro 1), diferentemente da escala planejada inicialmente, que atende à indicação da ASHRAE 55 (AMERICAN..., 2017), de 7 pontos. A métrica foi organizada de modo que uma resposta fosse destinada a sensação e percepção de frio, uma a neutralidade, e duas a sensação e percepção de calor. 
Figura 4 - Conjuntos edificados nas cidades de João Pessoa, Campina Grande e Cajazeiras
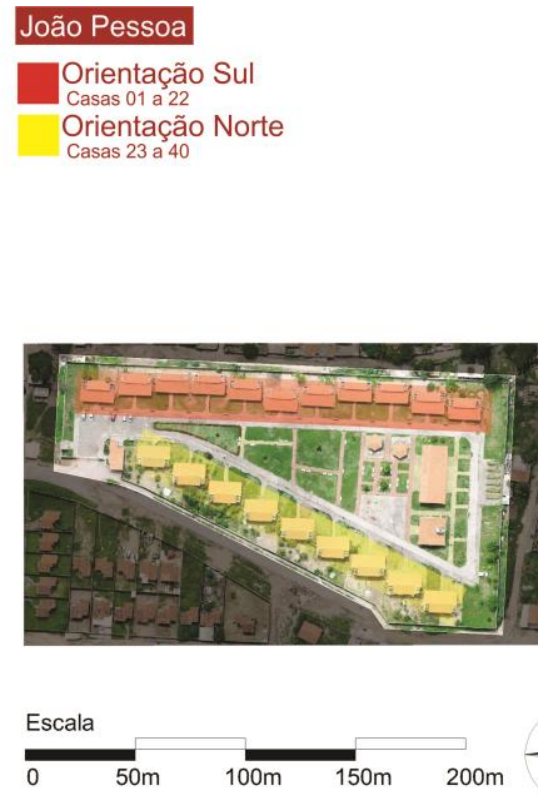

\section{Cajazeiras \\ Orientação Sul-sudeste} Casas 01 a 10

Orientação Oeste-sudoeste Casas 11 a 24

Orientação Norte-noroeste Casas 25 a 32

Orientação Este-nordeste

Casas 33 a 40

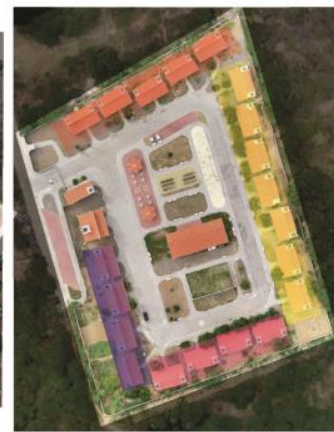

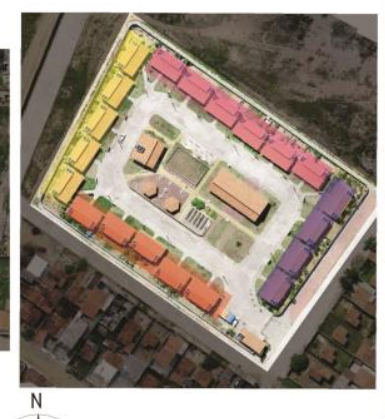

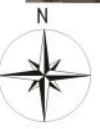

Fonte: modificada de CEHAP (COMPANHIA..., 2018).

Figura 5 - Planta baixa e foto da unidade habitacional

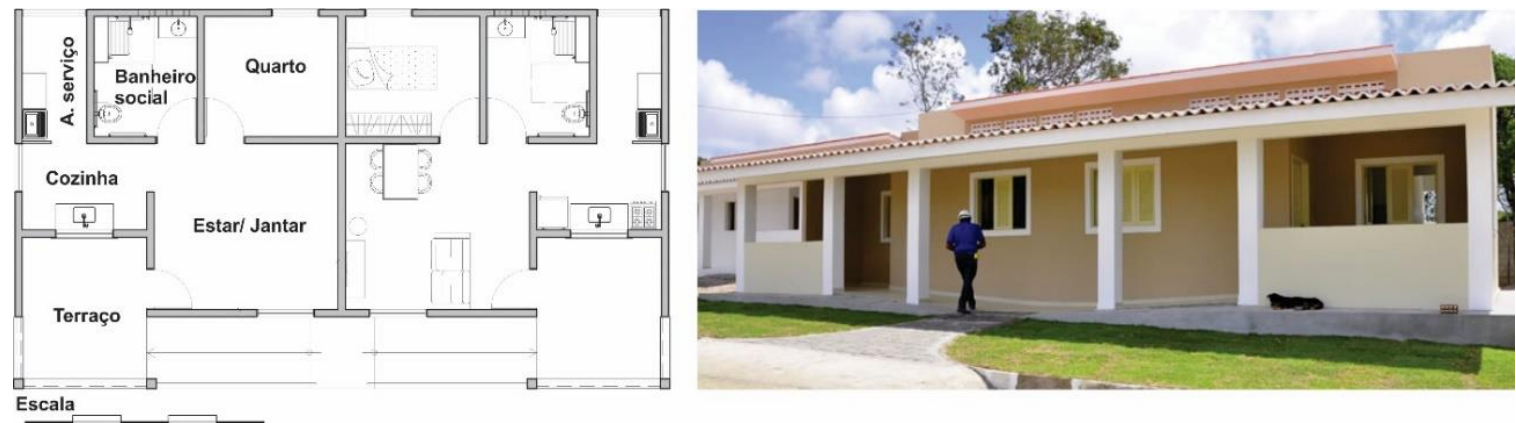

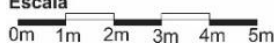

Fonte: CEHAP (COMPANHIA..., 2016).

Figura 6 - Camadas das paredes e lajes

Detalhe das paredes

Detalhe da Laje inclinada

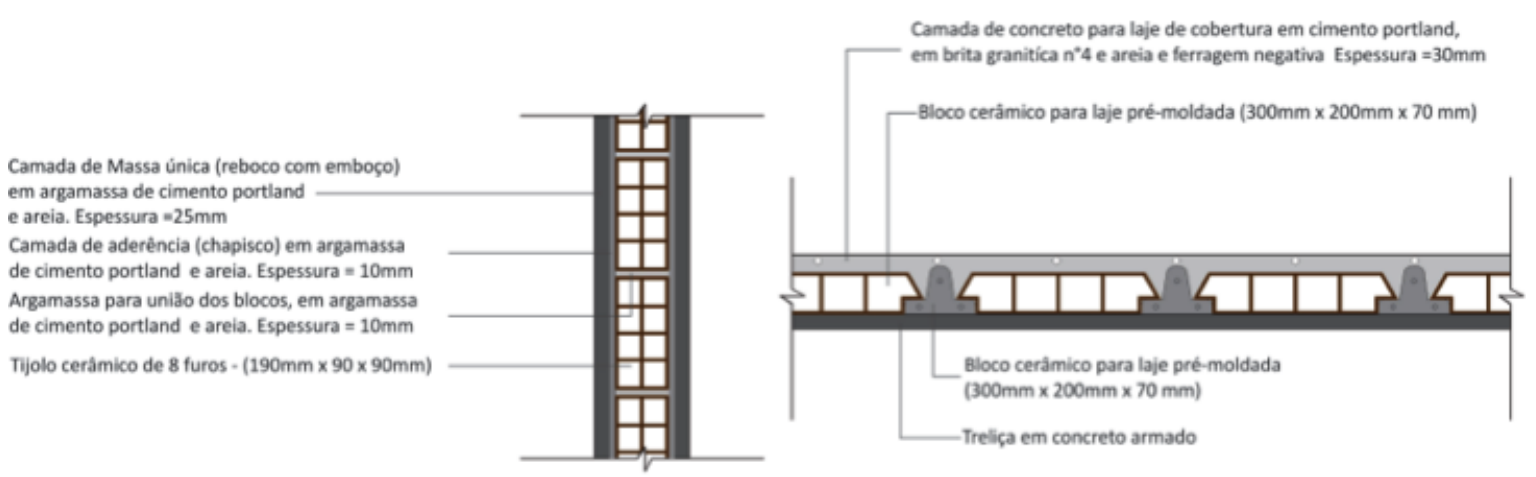

106 Silveira, J. G. da; Sousa M. C.; Leder, S. M. 
Quadro 1 - Perguntas utilizadas durante a entrevista semiestruturada

\begin{tabular}{|l|l|}
\hline Como classificaria sua casa em relação à temperatura? & $\begin{array}{l}\text { Muito quente; Quente; Nem quente, } \\
\text { nem fria; Fria }\end{array}$ \\
\hline Como classificaria sua casa em relação à ventilação? & $\begin{array}{l}\text { Muito ventilada; Pouco ventilada; Às } \\
\text { vezes venta; Não venta }\end{array}$ \\
\hline Com gostaria que sua casa fosse em relação à temperatura? & $\begin{array}{l}\text { Mais quente; Que se mantivesse } \\
\text { assim; Mais fria; Muito mais fria }\end{array}$ \\
\hline Como gostaria que sua casa fosse em relação à ventilação? & $\begin{array}{l}\text { Mais ventilada; Um pouco mais } \\
\text { ventilada; Que se mantivesse assim; } \\
\text { Que não ventasse }\end{array}$ \\
\hline Qual é o ambiente mais agradável em relação à temperatura? & $\begin{array}{l}\text { Sala; Cozinha/área de serviço; Quarto; } \\
\text { Banheiro }\end{array}$ \\
\hline $\begin{array}{l}\text { Qual é o ambiente mais desagradável em relação à } \\
\text { temperatura? }\end{array}$ & $\begin{array}{l}\text { Sala; Cozinha/área de serviço; Quarto; } \\
\text { Banheiro }\end{array}$ \\
\hline Qual o ambiente mais ventilado? & $\begin{array}{l}\text { Sala; Cozinha/área de serviço; Quarto; } \\
\text { Banheiro }\end{array}$ \\
\hline Qual o ambiente menos ventilado? & $\begin{array}{l}\text { Sala; Cozinha/área de serviço; Quarto; } \\
\text { Banheiro }\end{array}$ \\
\hline O sr.(a) mantém as portas internas dos ambientes abertas? & Horário de abertura e fechamento \\
\hline O sr.(a) mantém as janelas dos ambientes abertas? & Horário de abertura e fechamento \\
\hline Por qual motivo não as mantém abertas? & Sim; Não \\
\hline Costuma utilizar o ventilador? & \\
\hline O que o sr.(a) faz para aliviar o calor? & \\
\hline
\end{tabular}

\section{Amostra}

Os síndicos dos condomínios e a CEHAP não possuíam informações sobre o número total de moradores com mais de 60 anos, ainda mais porque alguns tinham parceiros flutuantes. Assim, considerou-se que havia 2 moradores por residência, totalizando 80 por condomínio. Não foi possível aplicar a aleatoriedade na seleção da amostra, pois foi observado in loco que alguns moradores tinham menos de 60 anos, alguns não foram encontrados em suas casas ou não tinham interesse em participar da pesquisa. Portanto, a amostra foi selecionada por conveniência compondo 90 entrevistas válidas distribuídas nos três condomínios estudados. Todavia, alguns entrevistados optaram por não responder a todas as perguntas. A coleta de dados foi realizada no interior da edificação, na sala de estar e jantar, entre as $9 \mathrm{~h} 00$ e as 20h00. A entrevista estruturada foi a forma de coleta dos dados subjetivos, que possibilitaram a apreensão das informações a respeito das opiniões dos moradores sobre sensações e percepções térmicas, e foi submetida ao Comitê de Ética do Centro de Ciências da Saúde (CCS) da Universidade Federal da Paraíba (UFPB), com o parecer favorável para prosseguimento do estudo de número 3.354.086.

\section{Monitoramento das variáveis ambientais}

A coleta de dados das variáveis ambientais térmicas ocorreu nos meses de janeiro e fevereiro de 2019. Todos os equipamentos utilizados nesta pesquisa foram submetidos a testes de confiabilidade, juntamente com equipamentos calibrados. Foram instaladas três estações meteorológicas (Figura 7), uma em cada condomínio, alocadas com um mínimo de 10 dias de antecedência às medições que foram realizadas no interior das unidades habitacionais. Desse modo, os dados referentes à temperatura externa se referem ao microclima dos condomínios.

As estações meteorológicas, do tipo Davis Vantage Pro, foram instaladas seguindo criteriosamente as recomendações de meteorologistas (considerando a problemática do estudo e as limitações dele), sendo os sensores de umidade relativa e temperatura do ar instalados na cota média de $1,50 \mathrm{~m}$ do piso, e o anemômetro com cota média de 2,50 m do piso. Todas as estações foram implantadas sobre área gramada, sem influência de edificações próximas ou de qualquer obstáculo, natural ou não. 
Figura 7 - Estação meteorológica instalada no município de Cajazeiras

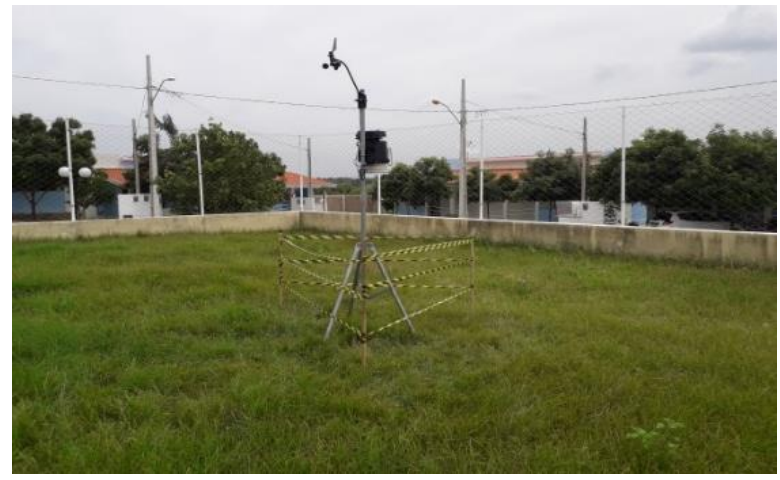

A coleta de dados no interior da edificação foi realizada através de dataloggers do tipo HOBO, com medição de temperatura do ar e umidade relativa do ar. Os equipamentos foram instalados nas salas das residências, a uma altura de 1,50 $\mathrm{m}$ do piso, juntamente com as estações meteorológicas, todos foram retirados ao final da pesquisa. Foram instalados $7 \mathrm{HOBO}$ em casas distintas nas cidades de Cajazeiras e Campina Grande, e o período considerado para as análises foi de 14 dias de medições (14 a 27 de janeiro). Em João Pessoa foram instalados em 4 casas, com 9 dias de medição (14 a 22 de janeiro).

\section{Análises descritivas e inferenciais}

Os dados foram tabulados com o software de organização em planilhas eletrônicas Microsoft Excel. Nessa plataforma foram realizadas todas as análises descritivas e parcela das inferenciais, o que incluiu análises de frequência (com geração de histogramas), média, moda, mediana, quantis, valores mínimos, máximos, criação de boxplots, gráficos de dispersão (a fim de estudar possíveis relações entre variáveis) e correlações de Pearson.

As demais análises inferenciais foram realizadas na plataforma estatística livre $\mathrm{R}$ Studio, mediante importação dos dados, conjecturando gráficos de dispersão com linhas de tendência, correlações de Kendall e Spearman, regressões lineares múltiplas e análises dos resíduos. As correlações de Spearman e Kendall foram realizadas quando as variáveis eram ordinais.

\section{Resultados e discussão}

\section{Sensação e preferência térmica}

Primeiramente foram analisadas descritivamente a sensação e a preferência térmica dos idosos dentro de suas residências, estudando-se a frequência das respostas dos entrevistados nas três cidades avaliadas. Os resultados, indiscriminada a região onde se localizam as casas, foram: $41 \%$ dos usuários referiram sua residência como "quente" ou "muito quente", $57 \%$ como neutra ("nem quente, nem fria") e apenas $2 \%$ como uma edificação "fria" (Figura 8). Adotando como parâmetro o da ASHRAE 55 (AMERICAN..., 2017), que considera como aceitáveis ambientes ventilados naturalmente que tenham $80 \%$ de aceitabilidade (entendida como neutralidade), entende-se que as edificações analisadas, como um todo, são consideradas termicamente desconfortáveis.

Em seguida, foi analisada a distribuição dos votos discriminando a região onde o entrevistado se encontrava, de modo a se obter um perfil de cada cidade. Em João Pessoa, observou-se que $79 \%$ dos votos se inseriram na categoria "nem quente, nem fria", e $21 \%$ na "quente", sendo este o condomínio que se situou mais perto do limite recomendado pela ASHRAE 55 (AMERICAN..., 2017).

Nas cidades de Campina Grande e de Cajazeiras os votos apresentaram menor concentração na categoria neutra. Acredita-se que essa distinção esteja relacionada com o fato de essas cidades se localizarem no semiárido e, consequentemente, terem maior amplitude térmica diária, quando comparadas a João Pessoa (cidade litorânea).

O condomínio em Campina Grande obteve 7\% dos votos na escala "muito quente", 35,7\% "quente" e 53,5\% "nem quente, nem fria", enquanto $3,6 \%$ dos votos foram atribuídos à condição "fria". Por outro lado, no 
condomínio de Cajazeiras houve uma concentração na condição quente, $7 \%$ dos entrevistados elegeram sua residência como "muito quente", $50 \%$ como "quente" e $43 \%$ como "nem quente, nem fria".

Quando os entrevistados foram questionados sobre como preferiam a temperatura de sua casa, os votos foram distribuídos da seguinte forma: $62 \%$ dos respondentes afirmaram que desejavam que ela fosse mais fria, enquanto $38 \%$ manifestaram desejo de que ela se mantivesse como se encontrava (Figura 9).

Comparando as respostas de como as pessoas observam termicamente suas residências e de como desejavam que elas fossem, identificou-se que o número de pessoas que desejavam que sua residência fosse mais fria é maior que o número de pessoas que consideram sua residência "quente", enfatizando que há uma preferência por condições térmicas mais amenas, mesmo nas pessoas aclimatadas a espaços quentes. Essa premissa foi sugerida por Humphreys e Nicol (2004).

Avaliando a preferência dos idosos por cidade, a distribuição das respostas foi: em João Pessoa, $42 \%$ votaram na categoria "que se mantivesse assim", $52 \%$ optaram pela condição "mais frio", e $6 \%$ na classe "muito mais frio"; na cidade de Campina Grande, $36 \%$ manifestaram desejo de "que se mantivesse assim", 57\% "mais frio" e 7\% "muito mais frio"; e em Cajazeiras, $36 \%$ optaram pela categoria "que se mantivesse assim", e 64\% preferiram a condição "mais frio". Esse panorama apontou que, independentemente da cidade avaliada, mais de $50 \%$ dos idosos manifestaram o desejo de ambientes com temperatura inferior, caracterizando a preferência dos idosos entrevistados por condições térmicas mais amenas do que aquelas vivenciadas por eles na habitação em análise.

Figura 8 - Frequência dos votos em relação à classificação da casa quanto à temperatura

Como classificaria sua casa em relação à

temperatura?

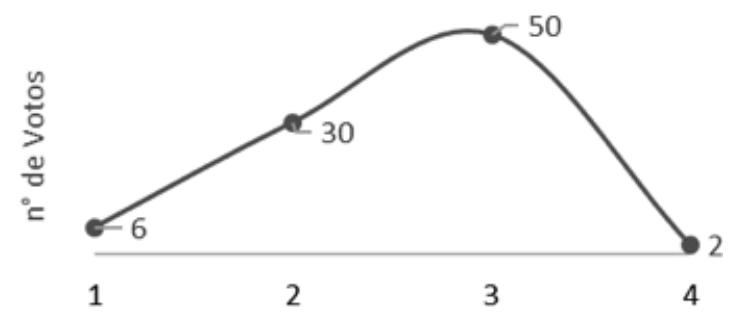

Nota: Legenda: $\rightarrow$

$1=$ Que se mantivesse assim;

2 = Mais frio; e

$3=$ Muito mais frio.

Figura 9 - Frequência dos votos em relação à classificação da casa quanto à preferência térmica

Como gostaria que sua casa fosse em relação à temperatura?

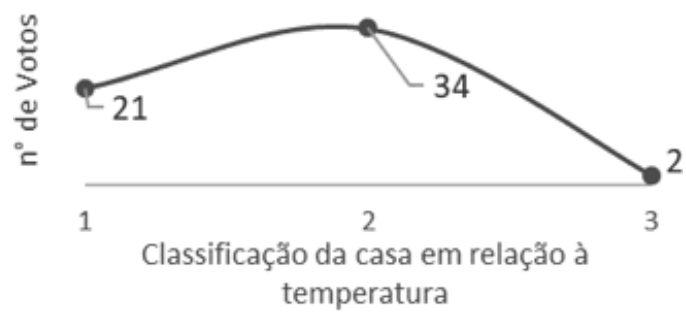

Nota: Legenda: $\begin{aligned} \longrightarrow & - \\ 1 & =\text { Que se mantivesse assim; } \\ 2 & =\text { Mais frio; e }\end{aligned}$

$3=$ Muito mais frio. 
Com o intuito de descobrir se existe correlação entre a sensação térmica no interior das residências e a preferência térmica dos moradores, a distribuição das respostas concomitantemente foi também analisada. Observou-se que, independentemente de o usuário perceber sua casa como "quente", "fria" ou "neutra", houve votos que preferiam as edificações "muito mais fria" ou "mais fria". Equivalentemente, houve idosos que consideravam suas casas "muito quente", "quente" ou "nem quente, nem fria", e responderam na categoria preferência que desejavam que a casa não sofresse alterações térmicas.

Considerando as variáveis preferência térmica e sensação térmica como categóricas ordinais, foi realizada a correlação de Kendall e de Spearman entre elas. As correlações foram de -0,32 e -0,33 respectivamente para Kendall e Spearman, portanto uma correlação fraca negativa, o que pode ser entendido como as pessoas com edificações quentes tendem a preferir edificações menos quentes, sendo a situação oposta também verdadeira. O gráfico de dispersão entre as variáveis pode ser observado na Figura 10.

Buscando possíveis influências entre as variáveis sensação e preferência térmica, foi gerada uma regressão linear, tendo como variável dependente a preferência térmica e como independente a sensação térmica. Considerando um nível de significância de 0,05 , a sensação térmica se mostrou uma preditora estatisticamente significante. Observando o algoritmo resultante (Figura 11), destaca-se que a preferência sempre tende mais para o frio em relação à sensação térmica.

Figura 10 - Dispersão entre as variáveis sensação e preferência térmica das residências

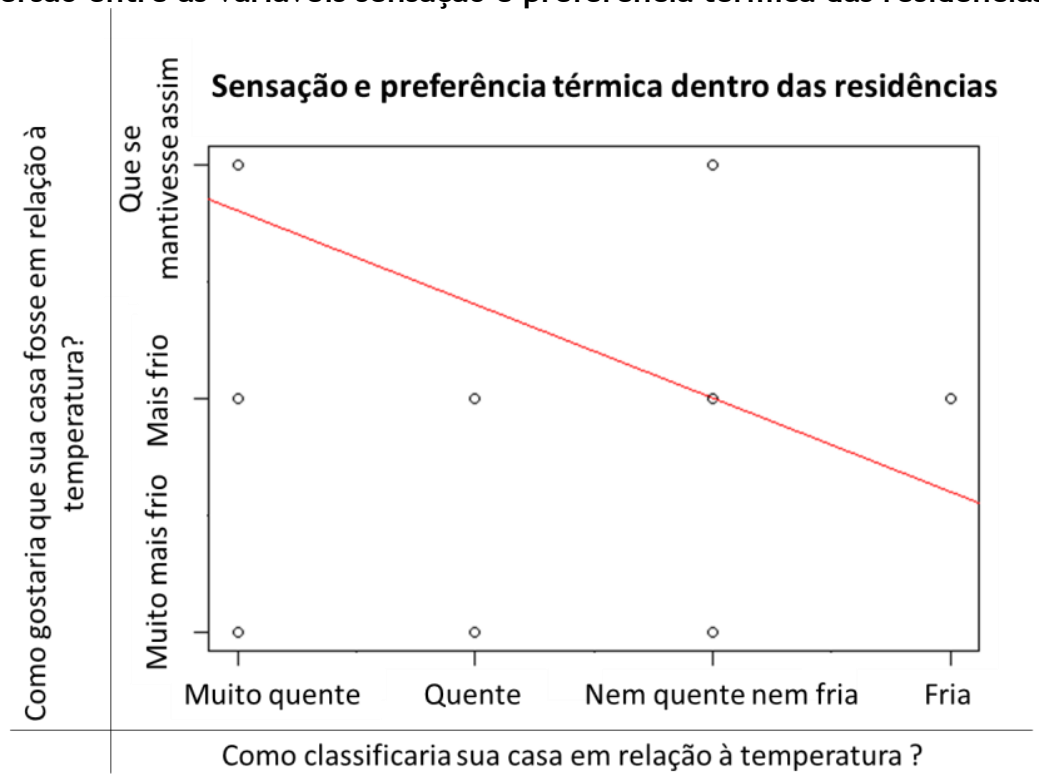

Figura 11 - Sensação e preferência térmica

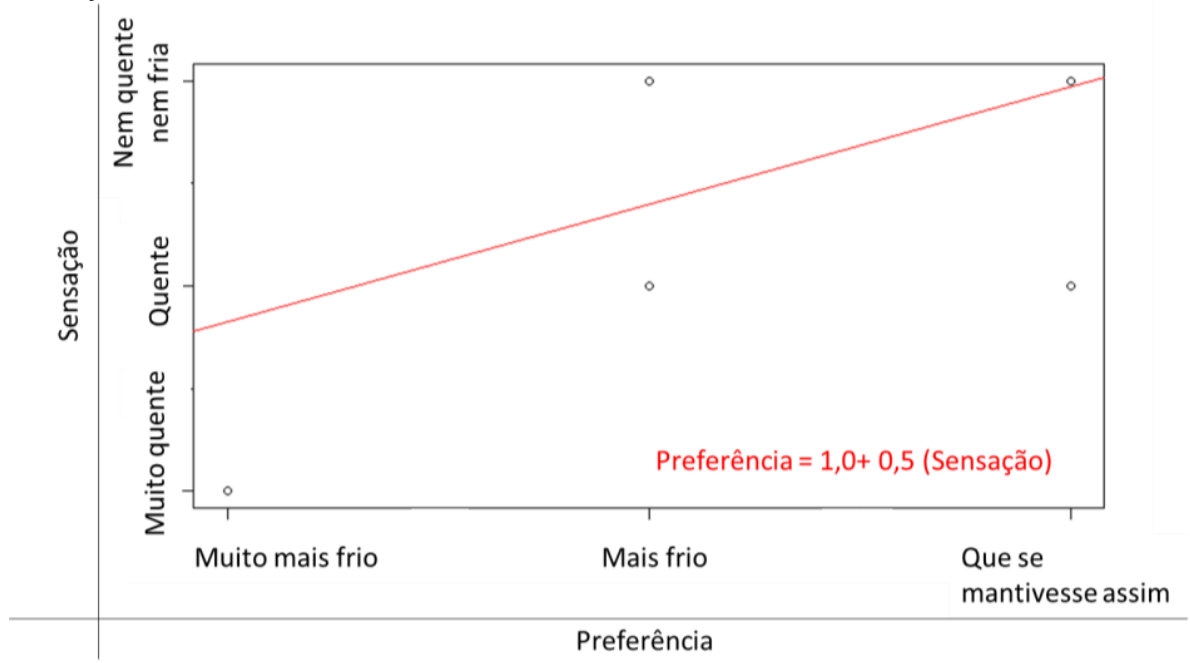

110 Silveira, J. G. da; Sousa M. C.; Leder, S. M. 
Outro aspecto analisado se refere à percepção dos idosos quanto à ventilação no interior da residência. A cidade de João Pessoa, com maior quantidade de votos neutros, teve o seguinte como disposição das preferências: $31 \%$ dos idosos relataram que a casa era "muito ventilada", $63 \%$ que era "pouco ventilada" e $6 \%$ que "às vezes venta". Na cidade de Campina Grande, a análise da sensação térmica foi em torno de 50\% com votos de neutralidade em relação à ventilação, $41 \%$ dos entrevistados elegendo sua casa como "muito ventilada", 44\% como "pouco ventilada", 11\% como "às vezes venta" e 4\% como "não venta". Por último, na cidade de Cajazeiras, cuja soma de votos de sensação térmica quente foi de $57 \%$, identificou-se que apenas $7 \%$ dos entrevistados consideraram sua casa "muito ventilada", sendo 54\% "pouco ventilada", 25\% "às vezes venta" e $14 \%$ "não venta".

Como pode ser visualizado por essa análise descritiva e no gráfico de dispersão entre as duas variáveis na Figura 12, existe uma possível relação entre a sensação térmica e a classificação dos usuários em relação à ventilação da casa. Assim, foram realizadas correlações para estudar a força dessa associação, e se ponderou uma fraca associação negativa entre as variáveis categóricas ordinais, de modo que os votos para edificações "muito quente" e "quente" ocorriam com mais frequência em edificações consideradas "sem vento" e "às vezes venta". A correlação de Spearman é de -0,17, e a correlação de Kendall, -0,16. Essa correlação baixa é explicada pela existência de outras variáveis que interferem na sensação térmica.

A sensação e a ventilação da casa foram também analisadas por ambiente, conforme pode ser visualizado nos gráficos de frequência da Figura 13. Os resultados, de acordo com as respostas dos idosos, apontaram que o ambiente mais quente da casa é o quarto, seguido da cozinha/área de serviço e da sala. Quando questionados sobre qual espaço da residência era o mais agradável, se excluído o terraço, teve-se como espaço mais agradável a sala, seguido da cozinha/área de serviço, banheiro e quarto. Assim, observou-se que o quarto, ambiente íntimo de prolongada permanência, foi considerado o espaço mais quente e menos agradável da residência, enquanto a sala foi avaliada como "menos quente e mais agradável”. Uma hipótese que pode explicar essa resposta, independentemente da orientação solar da casa, é que o terraço serve como uma área de sombreamento das paredes da sala, diminuindo sua carga térmica, ao mesmo tempo que existem duas aberturas de ventilação, a porta e a janela.

$\mathrm{Na}$ análise da ventilação dos ambientes discriminados constatou-se que a grande maioria dos entrevistados afirmou que a sala era o espaço mais ventilado, seguido da cozinha e do banheiro. Não foi contabilizado nenhum voto de ambiente mais ventilado para o quarto. Paradoxalmente, quando os idosos foram questionados qual ambiente da casa era o menos ventilado, a sala teve o maior número de votos, seguido da cozinha/área de serviço, banheiro e quarto. Observa-se, entretanto, que nessa categoria os votos foram distribuídos de modo mais uniforme, como pode ser observado na Figura 14.

Figura 12 - Dispersão entre as variáveis sensação térmica e ventilação das residências

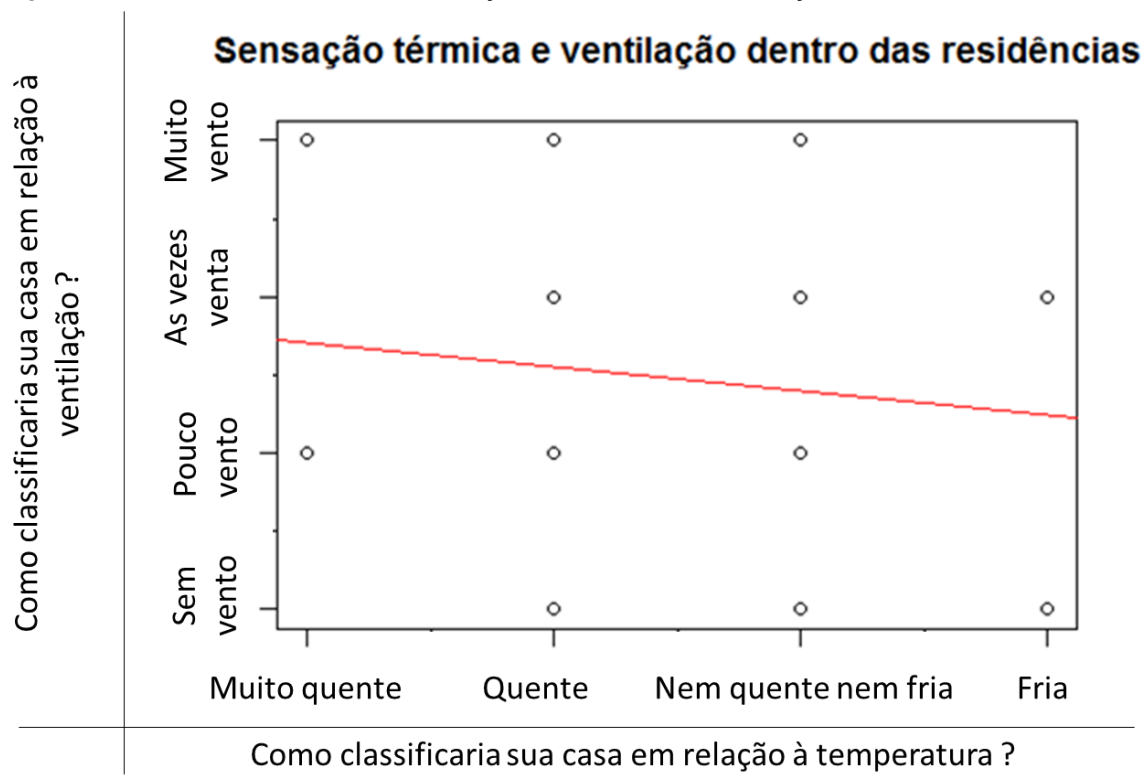

A percepção da ambiência térmica e as estratégias de adaptação: estudo de caso com idosos no clima tropical 111 
Figura 13 - Gráficos de frequência da sensação térmica discriminada por ambiente

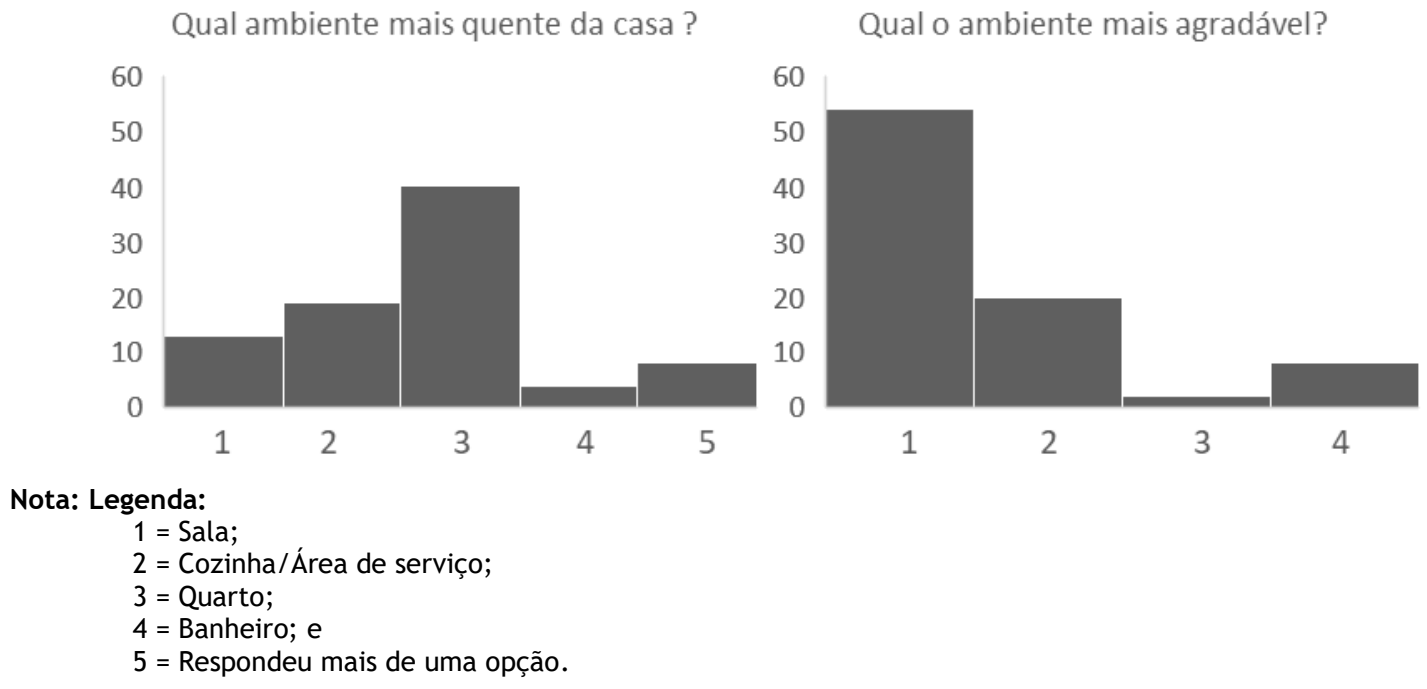

Figura 14 - Gráficos de frequência da ventilação discriminada por ambiente

Qual ambiente é o mais ventilado? Qual ambiente é o menos ventilado?

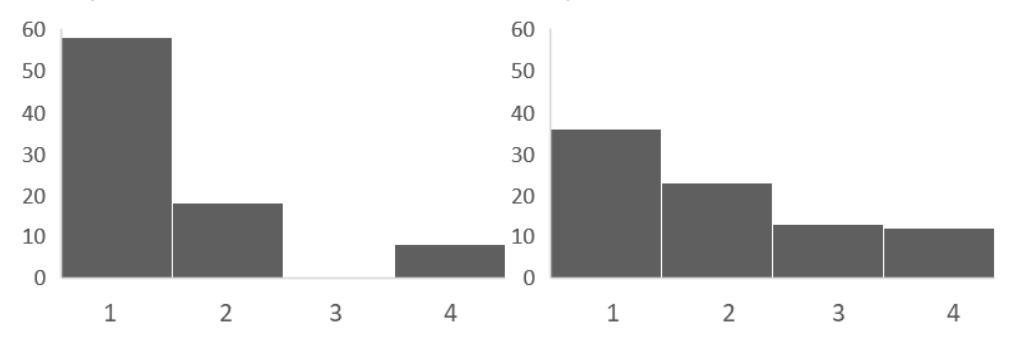

Nota: Legenda:

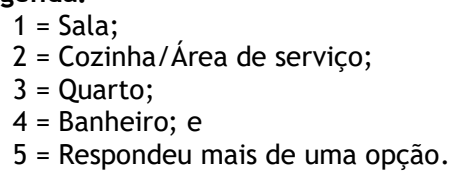

Após a análise descritiva dos votos, foi avaliada a existência de associações entre as respostas através da análise dos gráficos de dispersão. Observaram-se as nuvens de pontos e como elas se comportavam, quando concentradas ou dispersas (Figura 15). Posteriormente, analisaram-se essas relações por meio de correlações. Foi encontrada relação fraca entre o ambiente mais quente da casa e o mais agradável, com uma associação negativa de - 0,19 no método Kendall e de -0,20 no de Spearman, confirmando a tendência de os ambientes mais quentes serem considerados menos agradáveis. Já a relação entre o ambiente mais quente e o menos ventilado foi de 0,55 Spearman e de 0,50 Kendall, enfatizando significativa associação entre a ventilação e a sensação de conforto térmico. Por fim, considerando a relação entre o ambiente mais agradável e o ambiente mais ventilado, foi encontrada forte associação (positiva) tanto pelo método de Kendall $(0,64)$, quanto pelo de Spearman $(0,71)$.

A quantidade de horas que janelas e portas permanecem abertas também foi investigada. Sobre o tempo que as janelas ficavam abertas foi identificada uma média de $10 \mathrm{~h}$ por dia, com mediana de $12 \mathrm{~h}$ e moda de $0 \mathrm{~h}$. $\mathrm{O}$ intervalo variou de $0 \mathrm{~h}$ a $24 \mathrm{~h}$, com desvio padrão de 7,82.

Com o intuito de descobrir se as unidades habitacionais com maior tempo de abertura de janelas são consideradas confortáveis, foram realizadas correlações entre o tempo de abertura e a avaliação da ambiência térmica da habitação, contudo não foram encontradas associações significativas entre as variáveis, com o coeficiente de Pearson em módulo menor que 0,1. Por outro lado, quando analisada a opinião do entrevistado sobre a classificação geral da ventilação na residência associada ao tempo de abertura das janelas, foi encontrado coeficiente de Pearson igual 0,30. A associação positiva encontrada na correlação de Pearson sugere que, quanto maior o tempo de abertura das janelas, menor a sensação de que a casa é

112 Silveira, J. G. da; Sousa M. C.; Leder, S. M. 
ventilada. Portanto, os idosos que mantêm as janelas abertas por mais tempo consideram majoritariamente sua casa pouco ventilada.

Muitos moradores mantêm as janelas fechadas constantemente ou durante longos períodos. Sobre as razões da ação de fechar as janelas foi identificado: aparição de mosquitos no interior das residências (33\%), hábito de manter as janelas fechadas no período de sono (24\%) e necessidade de segurança (11\%). Por outro lado, $12 \%$ dos idosos relataram manter as janelas sempre abertas. A soma das principais razões do manuseio das janelas totaliza $80 \%$ das respostas válidas. A exclusão dos indivíduos que afirmaram nunca fechar as janelas muda o panorama das frequências, de modo que 38\% das respostas se concentrariam na aparição de mosquitos e 2,5\% de outros animais, o que inclui gatos, ratos e escorpiões. Esse dado reforça a importância da adoção de estratégias simples, como o uso de telas nas esquadrias, a fim de beneficiar o conforto e a salubridade da edificação. Um detalhamento maior das respostas pode ser visualizado na Figura 16.

Figura 15 - Agrupamento dos gráficos de dispersão entre as variáveis categóricas ordinais: ambientes mais quentes, mais agradáveis, mais ventilados e menos ventilados

Nota: Legenda:
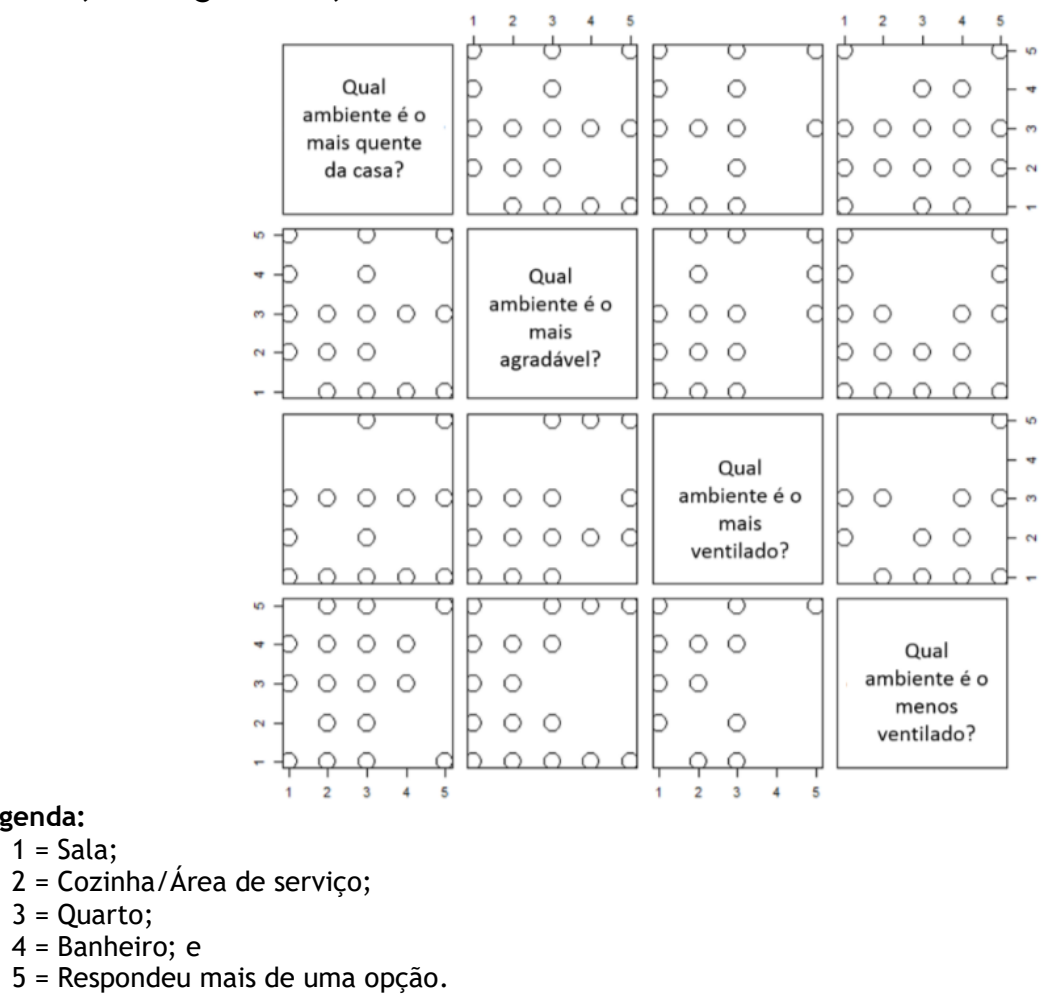

Figura 16 - Motivos que incitam os idosos a fechar as janelas

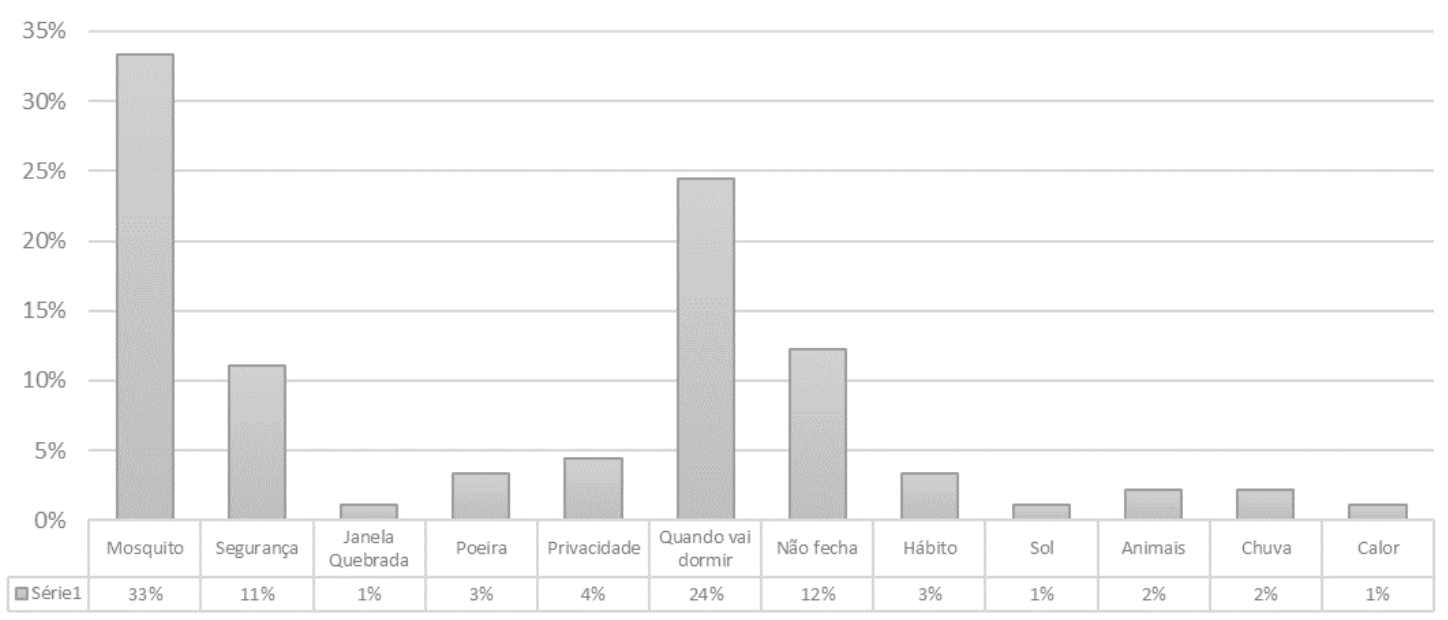


Foi verificado o horário de abertura e de fechamento das janelas, o que resulta na identificação do período no qual as janelas foram mantidas abertas. A questão tem como base a declaração do entrevistado de quando, normalmente, realiza a abertura e o fechamento das janelas da habitação (Figura 17). Identificou-se que na cidade de João Pessoa 26 idosos responderam a essa pergunta; destes, 23 afirmaram que abriam a janela entre $4 \mathrm{~h} 00$ e $6 \mathrm{~h} 00$ da manhã. O horário de fechamento, entretanto, variou bastante, com uma concentração de pontos no intervalo de $20 \mathrm{~h} 00$ a 22h00. Dos entrevistados, apenas $15(58 \%)$ afirmaram que deixavam a porta externa aberta. Quando questionados sobre a abertura das portas internas, $8(31 \%)$ disseram que a porta do quarto é mantida sempre aberta, enquanto a porta do banheiro é mantida fechada, 7 (27\%) deixavam ambas abertas, 1 entrevistado relatou manter a porta do banheiro sempre aberta e a do quarto fechada, e 1 entrevistado mantém as portas do quarto e do banheiro abertas apenas no turno noturno.

No condomínio em Campina Grande apenas 14 idosos relataram sobre o horário de abertura das janelas. Destes, 4 (28\%) afirmaram que as janelas são mantidas abertas continuamente. A concentração das nuvens de pontos (Figura 18) no horário de abertura se situou entre $5 \mathrm{~h} 30$ e as $7 \mathrm{~h} 00$, e a de fechamento, das $17 \mathrm{~h} 00$ às 19h30. Dos 25 entrevistados, apenas 10 (40\%) assumiram ter o hábito de manter a porta externa aberta por algumas horas, um deles tendo afirmado manter a porta externa sempre aberta. Os 9 restantes tiveram um tempo médio de abertura da porta externa de $11 \mathrm{~h} 40$. O questionamento sobre as portas internas indicou que $36 \%$ dos entrevistados sempre deixavam as portas fechadas, $48 \%$ sempre as tinham abertas, $8 \%$ tinham a porta do quarto aberta e a do banheiro fechada, e $4 \%$ tinham a porta do quarto fechada e a do banheiro aberta.

Figura 17 - Padrão de uso das janelas em João Pessoa

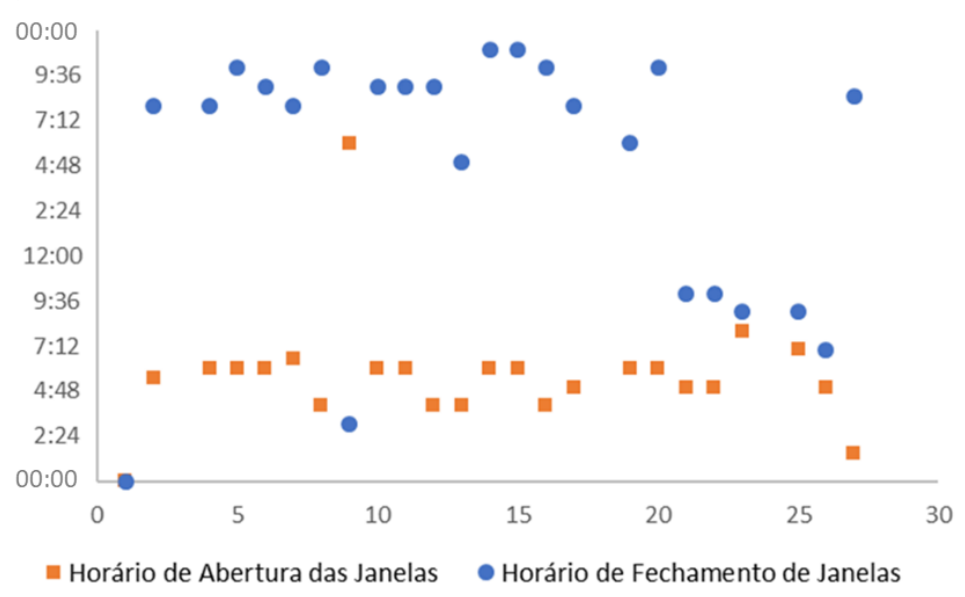

Figura 18 - Padrão de uso das janelas em Campina Grande

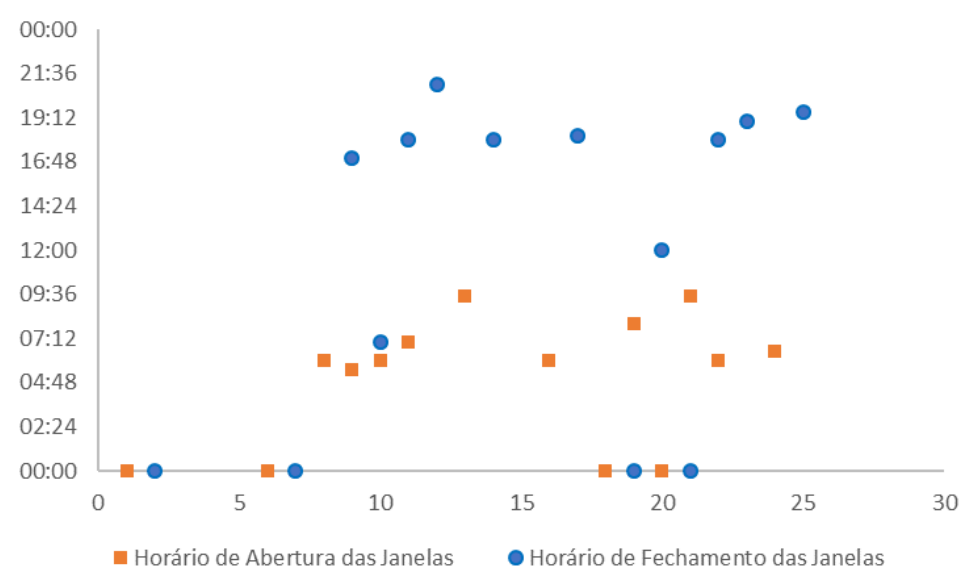

114 Silveira, J. G. da; Sousa M. C.; Leder, S. M. 
A cidade de Cajazeiras possui clima quente e seco. Embora a teoria aponte que o vento quente possa causar desconforto, empiricamente foi observado que os idosos abrem as janelas com relativa frequência, tendo 97\% dos entrevistados afirmado que as abrem diariamente. O gráfico de dispersão (Figura 19) mostra que o horário de abertura se concentra entre $4 \mathrm{~h} 00$ e $6 \mathrm{~h} 30$, e o de fechamento entre $15 \mathrm{~h} 00$ e $21 \mathrm{~h} 30$. Ressalta-se que $34 \%$ dos idosos afirmaram manter as janelas abertas o tempo inteiro. Assim como as janelas, os cajazeirenses também possuem o hábito de manter as portas externas abertas, um total de $76 \%$. O período médio de abertura foi de $8 \mathrm{~h} 16$, excluindo 5 entrevistados, que relataram manter a porta externa aberta durante todo o dia. Quanto à rotina de abertura e de fechamento de portas internas, $42 \%$ indicaram que sempre deixavam as portas abertas, $23 \%$ sempre deixavam fechadas, e $35 \%$ deixavam a porta do quarto aberta e a do banheiro fechada.

Ao serem questionados se usavam ventiladores, dos 25 respondentes na cidade de João Pessoa, 18 (72\%) indicaram que sim. Contudo, foi observada fraca correlação de Pearson $(-0,16)$, indicando que, quanto maior a percepção de "quente" em relação à residência, maior a probabilidade de uso do ventilador. A cidade de João Pessoa, clima quente e úmido, possui como uma das diretrizes bioclimáticas a ventilação permanente, assim a pequena correlação pode ser resultado da sensação de conforto gerada pelo uso do ventilador. Não foi encontrada correlação significativa (inferior a 0,05 de Pearson) entre a percepção da casa ventilada e o uso do ventilador (Figuras 20 e 21). Mais da metade dos idosos não soube informar quantas horas por dia utilizavam o ventilador, e os 14 indivíduos que responderam a essa pergunta relataram uma média de $14 \mathrm{~h}$ diárias.

Quando os idosos campinenses foram questionados sobre o uso de ventiladores, apenas 36\% indicaram que os usavam, entretanto apenas $44 \%$ desse número consideravam sua casa "quente", de modo que a maior parte das pessoas que usam ventiladores consideram a casa "fria" ou "nem quente, nem fria". A análise de correlação de Pearson entre o uso de ventiladores e a sensação da casa ventilada apontou que existe correlação moderada entre estes $(-0,33)$ : pessoas que consideram a casa pouco ventilada usam mais ventiladores (Figuras 22 e 23).

Figura 19 - Padrão de uso das janelas em Cajazeiras

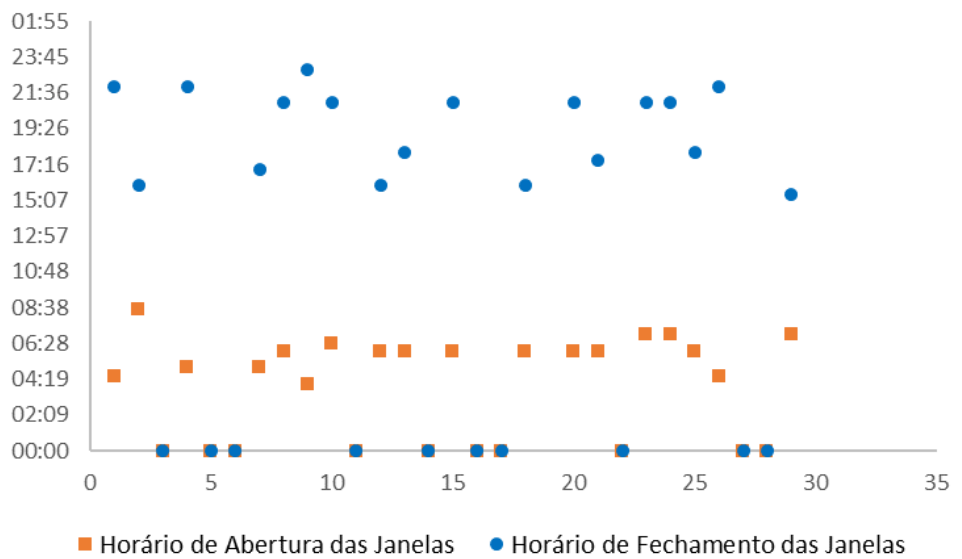

Figura 20 - Uso do ventilador x classificação da casa quanto à ventilação em João Pessoa

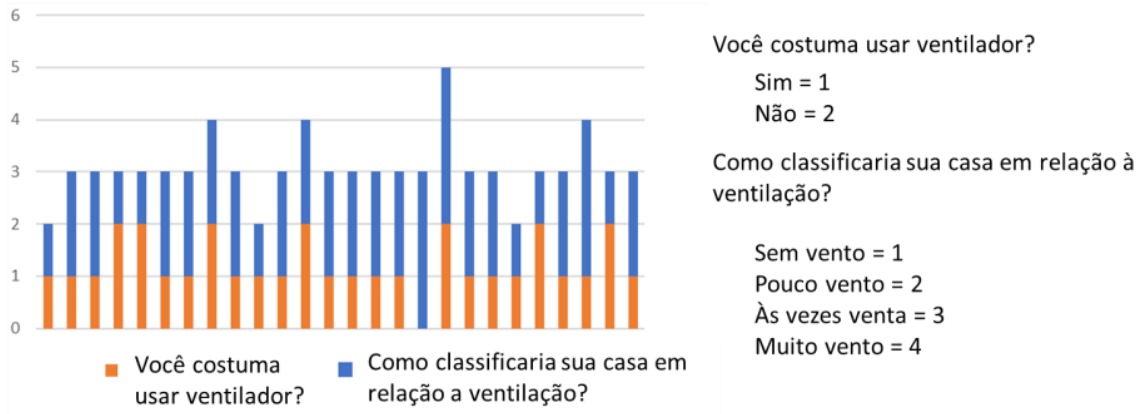

A percepção da ambiência térmica e as estratégias de adaptação: estudo de caso com idosos no clima tropical 115 
Figura 21 - Uso do ventilador x classificação da casa quanto à temperatura em João Pessoa

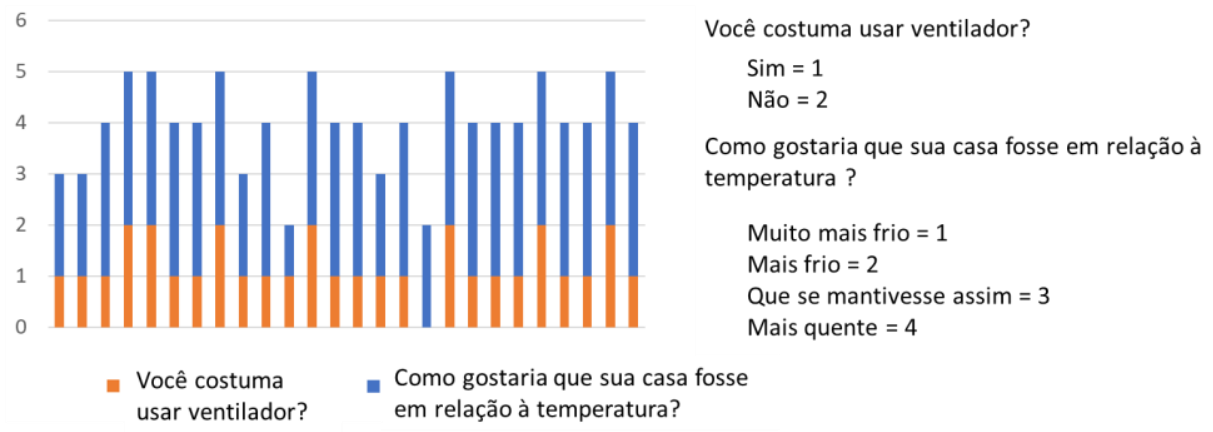

Figura 22 - Uso do ventilador x classificação da casa quanto à ventilação em Campina Grande

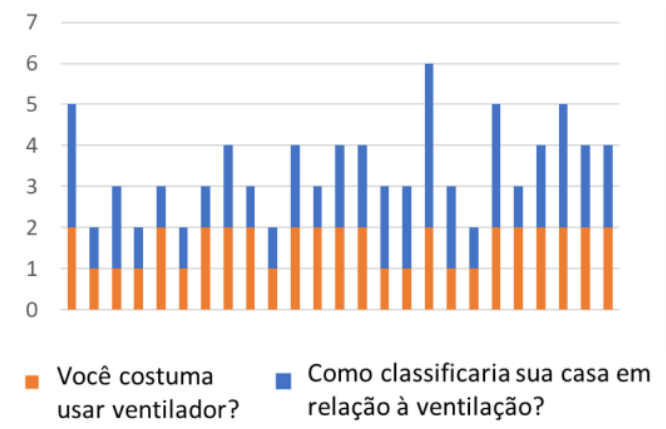

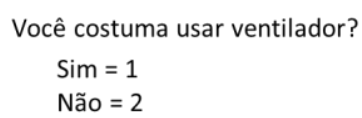

Como classificaria sua casa em relação à ventilação?

Sem vento $=1$

Pouco vento $=2$

Às vezes venta $=3$

Muito vento $=4$

Figura 23 - Uso do ventilador x classificação da casa quanto à temperatura em Campina Grande

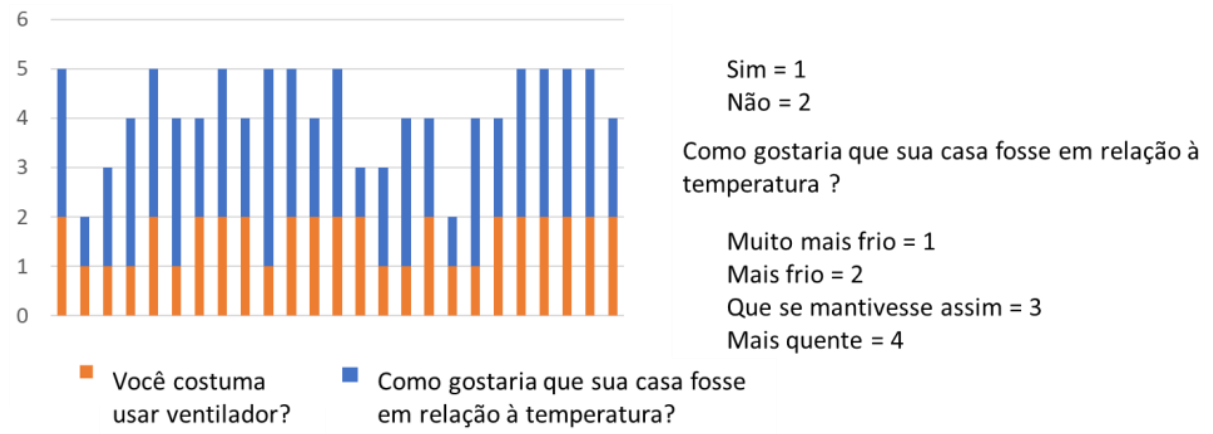

Sobre o uso de ventiladores no condomínio de Cajazeiras, $76 \%$ dos idosos afirmaram utilizar o equipamento. Observou-se correlação de Pearson de $-0,18$ entre a percepção da sensação térmica da casa e o uso de ventiladores, de modo que as pessoas que consideram a casa "quente" tendem a usar mais ventiladores. Ao analisar a correlação entre a percepção de ventilação da casa e o uso de ventilador, encontrou-se uma associação positiva de 0,17 , o que demonstra que as pessoas que afirmaram que a casa "não venta" tendem a usar menos o ventilador (Figuras 24 e 25).

Os idosos foram questionados sobre quais ações eles costumam fazer quando estão desconfortáveis termicamente pelo calor. Essa foi uma pergunta aberta, na qual eles podiam citar mais de uma estratégia (Figura 26). Cerca de 34\% das respostas afirmavam que eles se deslocavam para o terraço, informação que enfatiza a importância de espaços como esse para o público idoso; $26 \%$ tomavam banho; $14 \%$ bebiam algo gelado; e $11 \%$ usavam ventilador. Apenas 3\% das estratégias elencadas eram sobre o manuseio de esquadrias.

Por último, analisou-se a existência de possíveis associações entre o sexo e a classificação da casa em relação à sensação térmica, em relação à ventilação e em relação à preferência térmica. Os testes não encontraram nenhuma associação significativa, com todos os valores menores em módulo a 0,1. Assim, neste estudo de caso, o sexo não se mostrou uma variável influente nas análises. 
Figura 24 - Uso do ventilador x classificação da casa quanto à ventilação em Cajazeiras

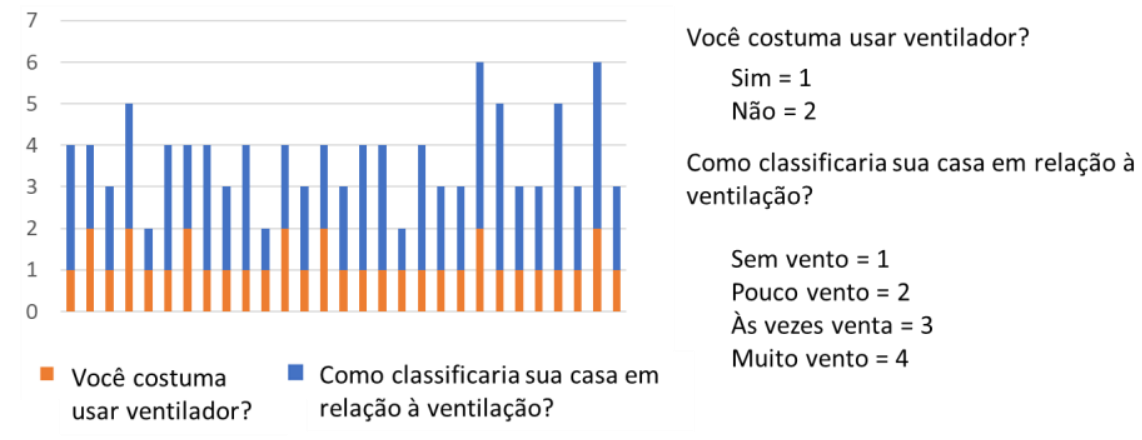

Figura 25 - Uso do ventilador x classificação da casa quanto à temperatura em Cajazeiras
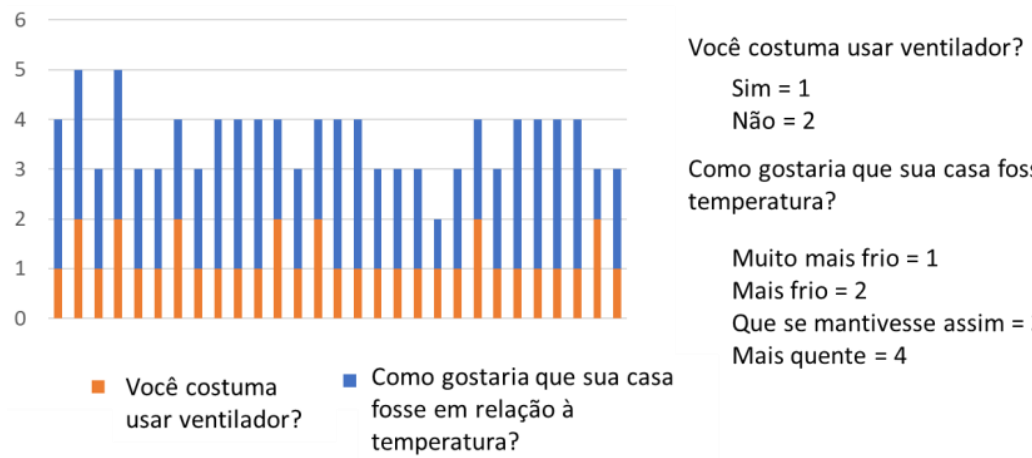

Figura 26 - Estratégias adaptativas para atingir o conforto térmico

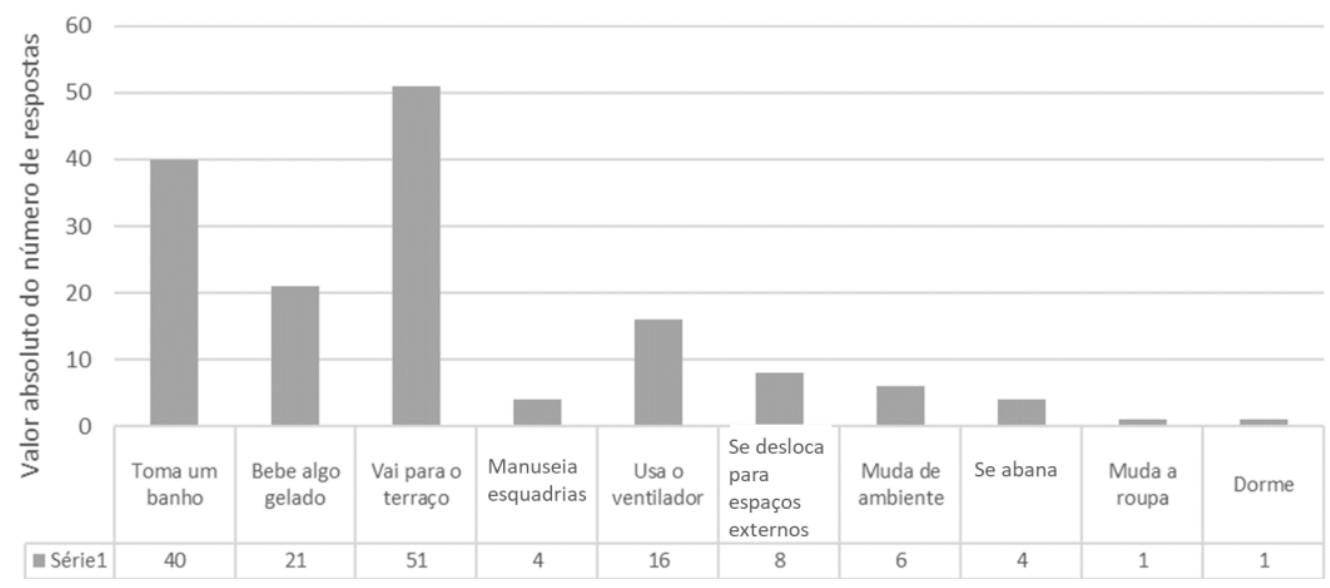

\section{Conclusões}

O envelhecimento populacional é um fenômeno de escala global. Estudos apontam que a percepção térmica humana varia conforme a idade, sendo os idosos um grupo descrito com maior vulnerabilidade. Assim, este artigo analisou as estratégias adotadas pela população idosa para a promoção do conforto térmico. Concomitantemente, foram observadas a sensação e a percepção térmicas de idosos residentes em conjuntos habitacionais inseridos no clima quente e úmido e semiárido.

Os idosos entrevistados relataram desejo por condições térmicas mais amenas, mesmo quando a sensação térmica relatada não era a de calor, o que evidencia a predominância da sensação de desconforto térmico por calor.

Foi constatado que os entrevistados consideram importante a velocidade do ar para a promoção do conforto. Contudo, identificou-se que muitos idosos mantêm as janelas de suas casas fechadas, reduzindo, assim, a 
possibilidade de ventilação natural para a obtenção do conforto. O motivo mais citado como impulsionador do fechamento das aberturas (janelas e porta externa) foi a entrada de insetos e de outros animais. Isso evidencia o uso de telas de proteção contra mosquitos nas esquadrias como um importante acessório na promoção do conforto térmico nas edificações analisadas. Outros aspectos, como segurança e hábitos culturais, estão associados à abertura das janelas e portas.

Os idosos entrevistados identificaram a sala como o ambiente mais agradável da casa, enquanto o quarto foi considerado o mais quente. Essa percepção térmica ocorreu em todas as cidades analisadas, independentemente da orientação da janela no recinto. Ocorre que a sala é o ambiente mais protegido da radiação solar direta e com possibilidade de ventilação cruzada. Uma hipótese para o quarto ser considerado mais quente é o fato de ser um espaço íntimo e, por isso, a janela deve ficar mais tempo fechada.

O uso do ventilador é uma estratégia muito utilizada, associada com o grau de desconforto da unidade habitacional, embora nem sempre seu uso esteja relacionado com o fato de a casa ser considerada quente. As estratégias adaptativas mais elencadas, quando em desconforto por calor, foram: deslocar-se para o terraço, tomar um banho, beber algo gelado e usar o ventilador. Não foi encontrada relação entre o sexo do entrevistado e sua descrição em relação à sensação e à percepção térmica da casa.

É necessário aprofundar o conhecimento sobre aspectos relacionados ao envelhecimento que sejam capazes de influenciar na percepção da ambiência térmica. Também se compreende a fundamental importância de estudar as diferenças na sensação, percepção e preferência térmica de idosos e adultos que estejam ocupando o mesmo espaço, preferencialmente em estudos de campo não controlados.

Por fim, ressalta-se que este estudo analisou idosos residentes em duas regiões. Para uma caracterização mais aprofundada do conforto térmico para esse público, serão necessárias mais pesquisas em climas diferentes desses investigados, para que haja dados suficientes para a elaboração de uma classificação que reflita os anseios e as dificuldades dessa população.

\section{Referências}

AMERICAN SOCIETY OF HEATING, REFRIGERATING AND AIR- CONDITIONING ENGINEERS IS AN AMERICAN). STANDARD 55-2017: thermal environmental conditions for human occupancy. Atlanta, 2017.

ANDERSEN, R.; FABI, V.; CORGNATI, S. Predicted and actual indoor environmental quality: verification of occupants' behaviour models in residential buildings. Energy and Buildings, v. 127, p. 105-115, 2016.

ASSOCIAÇÃO BRASILEIRA DE NORMAS TÉCNICAS. NBR 15220-3: desempenho térmico de edificações: parte 3: zoneamento bioclimático brasileiro e diretrizes construtivas para habitações unifamiliares de interesse social. Rio de Janeiro, 2003.

BAKER, N. V.; STANDEVEN, M. A. Thermal comfort in free-running buildings. Energy and Buildings, V. 23, n. 3, p. 175-182, 1996.

BRAGER, G.; PALIAGA, G.; DE DEAR, R. Operable windows, personal control and occupant comfort. ASHRAE Transactions, v. 110, n. 2, p. 17-35, 2004.

CHINDAPOL, S. et al. A suitable thermal stress index for the elderly in summer tropical climates. Procedia Engineering, v. 180, p. 932-943, 2017.

COMPANHIA ESTADUAL DE HABITAÇÃO POPULAR. Projeto Cidade Madura: João Pessoa. João Pessoa, 2016.

COMPANHIA ESTADUAL DE HABITAÇÃO POPULAR. Condomínios cidades maduras: imagens ortorretificadas. João Pessoa, 2018.

DAANEN, H. A. M; HERWEIJER, J. A. Effectiveness of an indoor preparation program to increase thermal resilience in elderly for heat waves. Building and environment, v. 83, p. 115-119, 2015.

D'OCA, S.; HONG, T. A data-mining approach to discover patterns of window opening and closing behavior in offices. Building and Environment, v. 82, p. 726-739, 2014.

DE DEAR, R.; BRAGER, G.; COOPER D. Developing an Adaptive Model of Thermal Comfort and Preference. Final Report: ASHRAE RP-884, 1997. 
DE VECCHI, R. Avaliação de conforto térmico em edificações comerciais que operam sob sistemas mistos de condicionamento ambiental em clima temperado e úmido. Florianópolis, 2015. $237 \mathrm{f}$. Tese (Doutorado em Engenharia Civil) - Programa de Pós-Graduação em Engenharia Civil, Universidade Federal de Santa Catarina, Florianópolis, 2015.

FABI, V. et al. Description of occupant behavior in building energy simulation: state of art and concepts for improvements. In: CONFERENCE OF INTERNATIONAL BUILDING PERFORMANCE SIMULATION ASSOCIATION, 12., Sydney, 2011. Proceedings [...] Sydney, 2011.

FAN, G. et al. Investigation of indoor thermal environment in the homes with elderly people during heating season in Beijing, China. Building and Environment, v. 126, p. 288-303, 2017.

GIAMALAKI, M.; KOLOKOTSA, D. Understanding the thermal experience of elderly people in their residences: study on thermal comfort and adaptive behaviors of senior citizens in Crete, Greece. Energy and Buildings, v. 185, p. 76-87, 2019.

GOOGLE EARTH PRO. [Imagens de satélite de varredura global,7.3.2.5491 (64-bit): kh.google.com]. 2017.

HALDI, F.; ROBINSON, D. The impact of occupants' behaviour on building energy demand. Journal of Building Performance Simulation, v. 4, n. 4, p. 323-338, 2011.

HUMPHREYS, M. A.; NICOL, J. F. Do people like to feel a "neutral"? Response to the ASHRAE Scale of subjective warmth in relation to thermal preference, indoor and outdoor temperature. ASHRAE Transactions, v. 110, p. 569-577, 2004.

INDRAGANTI, M. et al. Adaptive model of thermal comfort for offices in hot and humid climates of India. Building and Environment, v. 74, p. 39-53, 2014.

INSTITUTO BRASILEIRO DE GEOGRAFIA E ESTATÍSTICA. Projeção da população do Brasil e das Unidades da Federação. Disponível em: https://www.ibge.gov.br/apps/populacao/projecao/. Acesso em: 7 jan. 2020.

JIAO, Y. et al. The relationship between thermal environments and clothing insulation for elderly individuals in Shanghai, China. Journal of Thermal Biology, v. 70, p. 28-36, 2017a.

JIAO, Y. et al. Thermal comfort and adaptation of the elderly in free-running environments in Shanghai, China. Building and Environment, v. 118, p. 259-272, $2017 \mathrm{~b}$.

KOWALTOWSKI, D. C. C. K.; BERNARDI, N. Avaliação da interferência comportamental do usuário para a melhoria do conforto ambiental em espaços escolares: estudo de caso em Campinas-SP. In: ENCONTRO NACIONAL SOBRE CONFORTO NO AMBIENTE CONSTRUÍDO, 6.; ENCONTRO LATINO AMERICANO SOBRE CONFORTO NO AMBIENTE CONSTRUÍDO, 3., São Pedro, 2001. Anais [...] Campinas: ANTAC, 2001.

LIU, J.; YAO, R.; MCCLOY, R. A method to weight three categories of adaptive thermal comfort. Energy and Buildings, v. 47, p. 312-320, 2012

MA, T.; XIONG, J.; LIAN, i. A human thermoregulation model for the Chinese elderly. Journal of Thermal Biology, v. 70, p. 2-14, 2017.

MACHADO, R. S. P.; COELHO, M. A. S. C.; COELHO, K. S. C. Percentual de gordura corporal em idosos: comparação entre os métodos de estimativa pela área adiposa do braço, pela dobra cutânea tricipital e por bioimpedância tetrapolar. Revista Brasileira de Geriatria e Gerontologia, Rio de Janeiro, v. 1, n. 13, p. 17-27, out. 2010.

MALACHIAS, M. et al. $7^{\text {a }}$ diretriz brasileira de hipertensão arterial. Associação Brasileira de Cardiologia, v. 107, n. 3, p. 1-103, 2016.

NICOL, J. F.; HUMPHREYS, M. A. Adaptive thermal comfort and sustainable thermal standards for buildings. Energy and Buildings, v. 34, n. 6, p. 563-572, 2002.

NOVIETO, D. T.; ZHANG, Y. Year: thermal comfort implications of the aging effect on metabolism, cardiac output and body weight. In: NOVIETO, D. T.; ZHANG, Y. (ed.). Adapting to change: new thinking on comfort. London: Network for Comfort and Energy use in Buildings, 2010.

ORMANDY, D.; EZRATTY, V. Health and thermal comfort: from WHO guidance to housing strategies. Energy Policy, v. 49, p. 116-121, 2012. 
OROSA, J. A.; OLIVEIRA, A. C. A new thermal comfort approach comparing adaptive and PMV models. Renewable Energy, v. 36, p. 951-956, 2010.

PANET, M. de F. Um futuro confortável: modelagem preditiva de sensação térmica de pessoas idosas residentes em localidade do semiárido da Paraíba/Brasil. Natal, 2018. Tese (Doutorado em Arquitetura e Urbanismo) - Curso de Arquitetura e Urbanismo, Universidade Federal do Rio Grande do Norte, Natal, 2018.

PANTAVOU, K. et al. Evaluating thermal comfort conditions and health responses during an extremely hot summer in Athens. Building and Environment, v. 46, n. 2, p. 339-344, feb. 2011.

RAMOS, L. R. Fatores determinantes do envelhecimento saudável em idosos residentes em centro urbano: projeto epidoso, São Paulo. Cadernos de Saúde Pública, v. 19, n. 3, p. 793-797, jun. 2003.

ROELOFSEN, P. Healthy ageing: differences between elderly and non-elderly in temperature sensation and dissatisfied. Intelligent Buildings International, v. 9, n. 3, p. 123-136, 2017.

ROETZEL, A. et al. A review of occupant control on natural ventilation. Renewable and Sustainable Energy Reviews, v. 14, p. 1001-1013, 2010.

SALATA, F. et al. On the necessities to analyse the thermohygrometric perception in aged people: a review about indoor thermal comfort, health and energetic aspects and a perspective for future studies. Sustainable Cities and Society, v. 41, p. 469-480, 2018.

SCHNEIDER, R. H.; QUARTI IRIGARAY, T. O envelhecimento na atualidade: aspectos cronológicos, biológicos, psicológicos e sociais. Estudos de Psicologia, v. 25, p. 585-593, 2008.

SIMÕES, G. M. F. Conforto e adaptação espacial e individual em conjuntos habitacionais de interesse social: estudo em João Pessoa-PB. João Pessoa, 2018. Dissertação (Mestrado em Engenharia Civil) Programa de Pós-Graduação em Arquitetura e Urbanismo, Universidade Federal da Paraiba, João Pessoa, 2018.

SOCIEDADE BRASILEIRA DE DIABETES. Diretrizes da Sociedade Brasileira de Diabetes 2017-2018. São Paulo: Clannad, 2017.

TOCHIHARA, Y. et al. Age-related differences in cutaneous warm sensation thresholds of human males in thermoneutral and cool environments. Journal of Thermal Biology, v. 36, n. 2, p. 105-111, 2011.

VAN HOOF, J. et al. Ten questions concerning thermal comfort and ageing. Building and Environment, v. 120, p. 123-133, 2017.

WANG, Z. et al. Chinese older people's subjective and physiological responses to moderate cold and warm temperature steps. Building and Environment, v. 149, p. 526-536, 2019.

WANG, Z.; XIA, L.; LU, J. Development of adaptive prediction mean vote (APMV) model for the elderly in Guiyang, China. Energy Procedia, v. 142, p. 1848-1853, 2017.

WASSOUF, M. Da casa passiva à norma Passivhaus: a arquitetura passiva em climas quentes. Barcelona: Gustavo Gili, 2014.

\section{Agradecimentos}

O presente trabalho foi realizado com o apoio da Coordenação de Aperfeiçoamento de Pessoal de Nível Superior (Capes) - Código de Financiamento 001. 


\title{
Julio Gonçalves Silveira
}

Programa de Pós-Graduação em Arquitetura e Urbanismo, Centro de Tecnologia | Universidade Federal da Paraíba | Jardim Universitário, s/n, Campus I, Castelo Branco | João Pessoa - PB - Brasil | CEP 58051-900 | Tel.: (83) 98800-0239 | E-mail:

julio_goncalves_@hotmail.com

\section{Mayara Cynthia Sousa}

Programa de Pós-Graduação em Arquitetura e Urbanismo, Centro de Tecnologia | Universidade Federal da Paraíba | Tel.: (83) 3216-7913

| E-mail: frogoyo@hotmail.com

\section{Solange Maria Leder}

Departamento de Arquitetura, Centro de Tecnologia | Universidade Federal da Paraíba | Tel.: (83) 3216-7200 | E-mail:

solangeleder@yahoo.com.br

\author{
Ambiente Construído \\ Revista da Associação Nacional de Tecnologia do Ambiente Construído \\ Av. Osvaldo Aranha, $99-3^{\circ}$ andar, Centro \\ Porto Alegre - RS - Brasil \\ CEP 90035-190 \\ Telefone: +55 (51) 3308-4084 \\ Fax: +55 (51) 3308-4054 \\ www.seer.ufrgs.br/ambienteconstruido \\ E-mail: ambienteconstruido@ufrgs.br
}

(c) (i) This is an open-access article distributed under the terms of the Creative Commons Attribution License. 